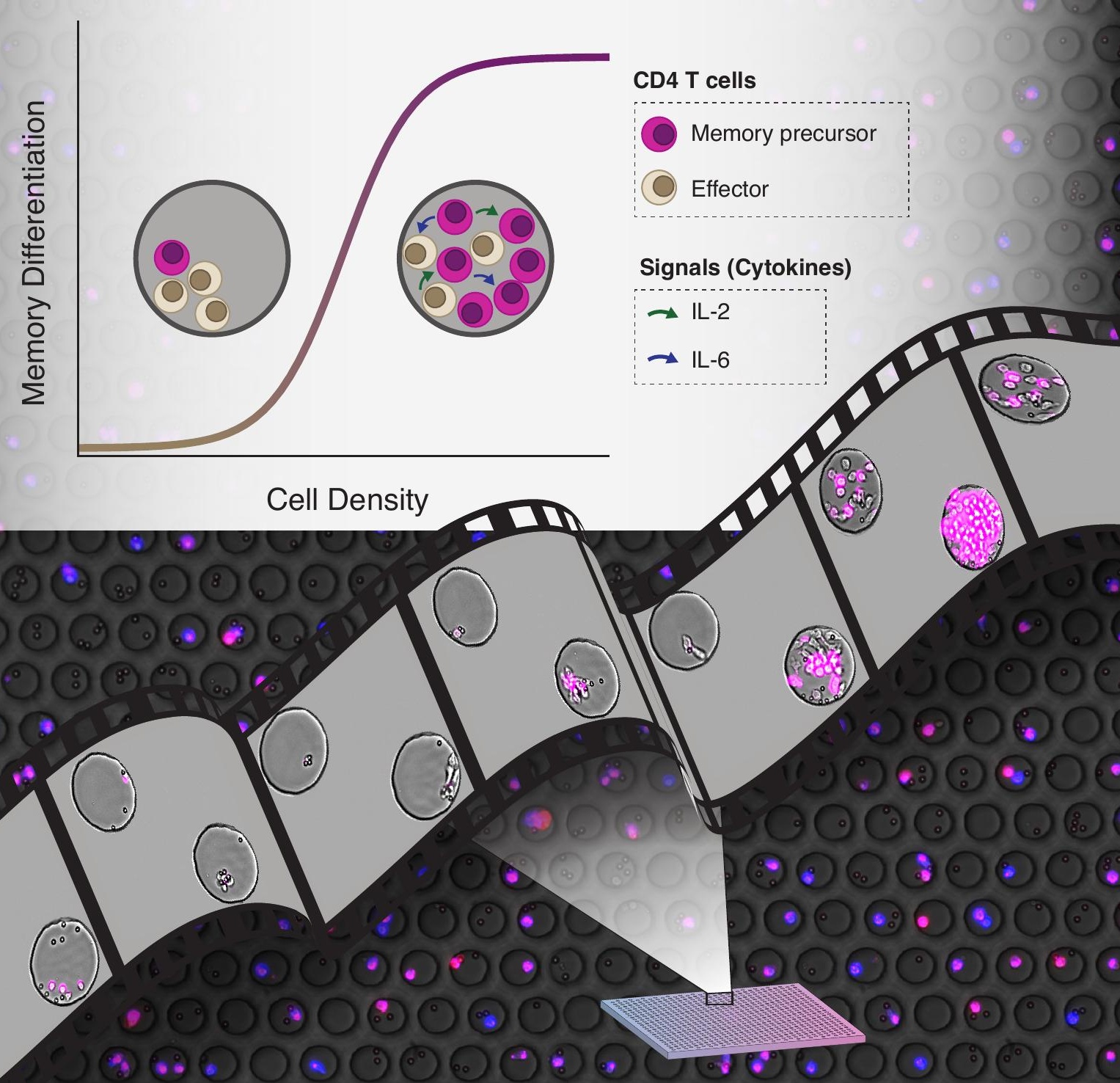




\section{Title: Induction of CD4 T cell memory by local cellular collectivity**}

Authors: Michal Polonsky ${ }^{1}$, Jacob Rimer ${ }^{1}$, Amos Kern-Perets ${ }^{1}$, Irina Zaretsky ${ }^{1}$, Stav Miller $^{1}$, Chamutal Bornstein ${ }^{1}$, Eyal David ${ }^{1}$, Naama Kopelman ${ }^{2 \dagger}$, Gil Stelzer ${ }^{2}$, Ziv Porat ${ }^{22}$, Benjamin Chain $^{3 *}$, Nir Friedman ${ }^{1 *}$

\section{Affiliations:}

1) Department of Immunology, Weizmann Institute of Science, Rehovot, Israel.

2) Life Sciences Core Facilities, Weizmann Institute of Science, Rehovot, Israel.

3) Division of Infection and Immunity, University College London, London, UK

$\dagger$ Currently at the Department of Computer Science, Holon Institute of Technology, Holon, Israel

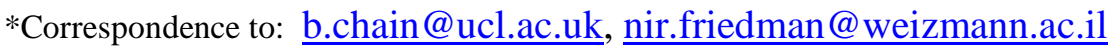

** "This manuscript has been accepted for publication in Science. This version has not undergone final editing. Please refer to the complete version of record at http:// www. sciencemag.org. The manuscript may not be reproduced or used in any manner that does not fall within the fair use provisions of the Copyright Act without the prior, written permission of AAAS."

\footnotetext{
Abstract: Cell differentiation is directed by signals driving progenitors into specialized cell types. This process can involve collective decision making, when differentiating cells determine their lineage choice by interacting with each other. We used live cell imaging in microwell arrays to study collective processes affecting differentiation of naïve $\mathrm{CD}^{+} \mathrm{T}$ cells into memory precursors. We found that differentiation of precursor memory $\mathrm{T}$ cells sharply increases above a threshold number of locally interacting cells. These homotypic interactions involve the cytokines IL-2 and IL-6, affecting memory differentiation orthogonal to their effect on proliferation and survival. Mathematical modeling suggests that the differentiation rate is continuously modulated by the instantaneous number of locally interacting cells. This cellular collectivity can prioritize allocation of immune memory to stronger responses.
} 
One Sentence Summary: The generation of precursor memory $\mathrm{CD}^{+} \mathrm{T}$ cells is a collective process driven by local homotypic interactions, involving the cytokines IL-2 and IL-6, orthogonal to their effect on cell proliferation and survival.

\section{T cell number influences CD4 memory formation in vivo and in vitro}

Upon recognition of a cognate antigen, naïve $\mathrm{T}$ cells expand and differentiate into various effector and memory cell types. The establishment of efficient acquired immune responses depends on an adequate balance between these cellular populations. Various models have been proposed to describe the mechanisms that drive $\mathrm{T}$ cell specialization, including cellautonomous stochastic processes (1-3), deterministic differentiation in response to external signals $(4,5)$ and asymmetric cell division (5-7). A number of studies have shown that the function and phenotype of $\mathrm{CD}^{+} \mathrm{T}$ cells expanding in response to antigen stimulation in vivo depends on the number of responding T cells (8-10). Specifically, central memory $\mathrm{T}$ cell (TCM) differentiation is enhanced when a larger number of $\mathrm{T}$ cells participate in the response. We observed a similar dependency on cell number in early $\mathrm{CD}^{+} \mathrm{T}$ cell differentiation into $\mathrm{CD} 44^{+} \mathrm{CD} 62 \mathrm{~L}^{+}$cells (hereafter referred to as progenitor central memory T cells, pTCM) in vivo, already five days following the vaccination of mice with a cognate antigen (Fig. 1A-B).

$\mathrm{T}$ cells differentiate in a complex environment in vivo, interacting with several cell types over time. Thus, we asked whether a dependence on precursor numbers can be observed in a minimal ex vivo system, in which cellular composition and concentration, and cell-cell interactions can be manipulated and monitored more easily. We isolated naïve splenic $\mathrm{CD}^{+} \mathrm{T}$ cells and cultured them at increasing concentrations in vitro. These $\mathrm{T}$ cells were activated either by OVA peptide presented by dendritic cells (Fig. 1C-top), by anti-CD3 + anti-CD28-coated microbeads (Fig. 1C-bottom, Fig. S1A-C), or by phorbol myristate 
acetage (PMA) + ionomycin (Fig. S1D). Cell state was evaluated using flow cytometry at different time points. Regardless of cell density and the mode of stimulation, the expression of CD62L decreased to its lowest level $24 \mathrm{~h}$ after activation and then increased in a densitydependent manner (Fig. S1B). Increasing cell density resulted in an increased fraction of pTCM cells in response to all activation regimes (Figs. 1C, S1 and Table S1). The maximal fraction of pTCM cells was different for the different stimulations used, potentially reflecting differences in strength of activation, which have been shown to influence T cell differentiation (11). A dependency on cell density was not observed for the activation markers CD69 and IL2Ra (Fig. S1B-C, Table S1). Differences in pTCM frequencies were apparent $48 \mathrm{~h}$ after activation and lasted for at least $96 \mathrm{~h}$ (experimental end point, Fig. 1C; Fig. S1B-C).

\section{pTCM isolated from 72 hour cultures exhibit a gene expression pattern that is characteristic of established central memory $T$ cells and persist over long time periods in vivo}

To further characterize the phenotype of early differentiated pTCM cells, CD62L- and $\mathrm{CD}_{2} \mathrm{~L}^{+}$cells were sorted after $72 \mathrm{~h}$ of culture. Each sorted group was subjected to genomewide gene expression analysis using RNA-seq. Together with CD62L ( Sell), the expression of other T cell central memory-related genes such as $C d 27, \operatorname{Il7} r, C c r 7$, and $I L 2 r b(7,12-$ 16) was elevated in $\mathrm{CD}_{6} \mathrm{~L}^{+}$cells. The expression of transcription factors (TFs) implicated in memory differentiation such as Klf2, Tcf7, Bcl6, Foxol and Eomos (17-22) were also increased (Fig.1D). Thus, pTCM in culture were associated with a transcriptional program that resembles that of more mature memory T cells. Early expression of a transcriptional program resembling that of mature TCM cells was recently observed also in CD8+ T cells, 2-4 days after in vivo infection $(7,23)$. CD62 $\mathrm{L}^{-}$cells expressed high levels of the TF Id2, which has been associated with the inhibition of memory differentiation $(24,25)$. These cells also expressed higher levels of cell cycle and apoptosis-related genes (Fig. 1D) such as $C d k n 1 a, M y c$, and $\operatorname{Casp3}(26,27)$, whereas $\mathrm{CD}_{2} \mathrm{~L}^{+}$cells expressed higher levels of homeostatic and self-renewal genes such as Grap2 and Cd4 (28). This differential gene expression is consistent with our observation that $\mathrm{CD}_{2} 2 \mathrm{~L}^{+}$cells exhibited a lower rate of proliferation compared with CD62L- cells in our culture system (Fig. S2). Gene ontology 
(GO) enrichment analysis (Fig. 1E) revealed that $\mathrm{CD}^{2} \mathrm{~L}^{-}$cells are enriched for genes related to apoptosis, ribosomal activity, and nucleotide metabolic processes, suggesting increased cell growth as well as cell death for these cells. CD62 $\mathrm{L}^{+}$cells were enriched for genes related to cytokine responses, leukocyte activation, and proliferation. $\mathrm{CD} 62 \mathrm{~L}^{+}$cells were also enriched for genes associated with cell communication and adhesion, consistent with a role for intercellular interactions in modulating pTCM differentiation.

Initial culture densities also influenced the long term in vivo persistence of adoptively transferred T cells. Cells activated at high density in vitro persisted more in vivo, and were four-fold more abundant at late time points ( $>35$ days after in vivo transfer) compared with cells pre-cultured at low density (Fig. 1F). Transferred cells expressed high levels of the memory markers CD62L and CD27 and low levels of the activation marker KLRG1 (which is high on $\mathrm{T}$ effector cells) relative to host cells (Fig. S3B). These results suggest the acquisition of an established central memory phenotype following short-term in vitro stimulation at high cell densities.

\section{pTCM formation is induced by local cellular collectivity}

The increased differentiation of pTCM cells at high cell densities can arise either from global changes in the composition of the culture medium through cytokine secretion by $\mathrm{T}$ cells, or by local interactions between activated cells. T cells in culture rapidly form dense dynamic clusters. Cells join and leave the clusters over time, and clusters can join to form larger clusters, or break into smaller ones (29). Thus, in conventional cell cultures as well as in vivo, it is difficult to distinguish the effect of local interactions within cell clusters from global long-range interactions. To overcome these difficulties, we used a culture system that employs microwell arrays at the bottom of the culture plate (30). Naïve T cells were seeded within small deep microwells (diameter $=80 \mu \mathrm{m}$, depth $=120 \mu \mathrm{m}$ ) together with microbeads coated with anti-CD3 + anti-CD28 antibodies for activation. Cell seeding was random, such that each microwell held a different number of cells at the beginning of the experiment (Fig. 2A and Figs. S4 and S5A). We followed the expansion and differentiation of cells within the microwells by live cell imaging (Fig. 2A-B). Cells were imaged for $96 \mathrm{~h}$ and the levels of expression of CD44 and CD62L were measured using live antibody stain ((31); Fig. 2A-B, see also supplementary movie S1). For each 
microwell, we extracted time traces of CD44 and CD62L levels, and the area covered by cells, which linearly correlated with cell number (see Fig. S5B).

The average CD62L and CD44 expression dynamics in the microwells highly resembled those observed using flow cytometry of bulk cultures (Fig. S5C). We found that the expression of CD62L, but not of CD44, was dependent on the initial number of $\mathrm{T}$ cells in the microwell, $N_{0}$. In wells initially containing 1-2 cells, CD62L was expressed only in a small fraction of the cells at late time points $(t=72$ to $96 \mathrm{~h})$, whereas in microwells initially containing > 7 cells CD62L was expressed by most cells at these times (Fig. 2B-C). Moreover, the re-expression of CD62L occurred earlier in microwells with a high initial cell number (Fig. 2B). The level and timing of CD44 expression however, did not depend on the initial cell number (Fig. 2B-C). CD62L expression in microwells was consistent with that obtained in conventional culture (Fig. 1C), as higher cell densities enhance differentiation towards pTCM in both cases. However, the microwell culture established that this effect was local, and was restricted to cells within individual microwells. Indeed, cells in neighboring microwells, which share culture medium, can have different differentiation frequencies based on their initial cell number, despite their proximity (Fig. S4). CD62L expression did not depend on the number of activating microbeads (Fig. S5D, Table S1), precluding competition for a limited amount of stimulatory signals as a cause for enhanced pTCM formation. Thus, the observed collective behavior was driven by shortrange interactions which modulated the differentiation of cells within the same microwell.

\section{Collective pTCM differentiation is a continuous process depending on the instantaneous number of interacting $\mathbf{T}$ cells}

Based on these results, we then sought to assess the mechanisms that drive collective differentiation. In particular, we asked whether differentiation depends on the number of cell divisions, on the initial number of interacting cells, or on the varying number of cells that interact (which grows with time due to cell proliferation). This analysis is typically complicated by the fact that the acquisition of a pTCM cell state occurs in parallel with cell proliferation. Thus, it is difficult to distinguish direct mechanisms that affect the differentiation process itself, and are not mediated indirectly by their effect on cell proliferation. We found that the number of cell divisions was not a major factor in 
regulating pTCM formation, as cells cultured in high cell density had higher CD62L expression compared with cells that had the same number of divisions but came from a culture of low cell density (Fig. S6). The microwell assay further demonstrated that proliferation did not display the collective characteristic we observed for CD62L induction. While the expansion dynamics of cells in individual microwells were highly variable even when starting from the same initial cell number (Fig 2D), the average proliferation rate was independent of $N_{0}$ (Figure 2E, Table S3).

Further insight was gained by examining the relationship between cell area and differentiation within individual microwells. We defined a critical time $(T c)$ at which $50 \%$ of the cells in a microwell were differentiated $\left(\mathrm{CD}^{2} \mathrm{~L}^{+}\right)$, and a critical area $(A c)$, which is the total cell area at $T c$ (Fig. 2F-H). When comparing single traces of two representative microwells starting with one (blue) or four (red) initial cells, we found that $A c$ was almost identical in both cases, whereas $T c$ was much higher in microwells that started with one cell (Fig. 2H). Looking at all microwells $\left(1 \leq N_{0} \leq 10\right)$, we found that the average $A c$ is independent of initial cell number (Fig. 2F), whereas $T \mathrm{c}$ decreases as initial cell numbers increase (Fig. 2G). A distinct behavior was observed for CD44, for which $T c$ is constant, and $A c$ increases with $N_{0}$ (Fig. S11A).

When the fraction of $\mathrm{CD} 62 \mathrm{~L}^{+}$cells was plotted as a function of total cell area in individual microwells, we found that both traces collapsed onto the same trajectory (Fig. 2I). This suggests that the level of differentiation does not depend on time from activation or on the level of cell proliferation, but rather on the instantaneous number of interacting cells. We generalized this observation by projecting all data points of all microwells (regardless of the number of initial cells, time from cell activation, or amount of cell proliferation) onto the area-CD62L plane (Fig. 2J, left). The normalized heat map showed that cells in individual microwells tended to follow a universal trajectory in the area-CD62L plane. We represented this trajectory with a "collective differentiation curve" (CDC), which we defined by the local maxima of the heatmap. Thus, the CDC describes the most commonly observed fraction of differentiated cells for a given number of cells in a microwell. The CDC, averaged over eight individual experiments, is plotted in Figure $2 \mathrm{~J}$, right. For further analysis, the CDC was fitted by a logistic function of the form $F(N)=$ 
$M /\left(1-e^{\left(-r\left(N-N_{C}\right)\right)}\right)$, where $N$ is the number of cells in the microwell (which can change with time), $N c$ is a critical cell number above which differentiation is more efficient, $M$ the maximal differentiation fraction, and $r$ defines the steepness of the curve.

The existence of a universal differentiation trajectory, which describes all microwells regardless of $N_{0}$, was consistent with the above observation that the mean $A c$ does not depend on $N_{0}$, whereas $T c$ decreases with $N_{0}$ (Fig. 2F-G, Table S1). Additional support for a universal differentiation trajectory came from global gene expression analyses performed at different time points. Cells that grow at low densities followed similar changes in their gene expression pattern but with a delay compared with cells that grow at high cell densities (Fig. S7).Together, these findings provide a strong indication for a collective process in which the acquisition of a pTCM state depends on the instantaneous number of interacting cells.

\section{Stochastic simulation re-capitulated experimentally observed collective differentiation}

To gain a better understanding of the cellular processes giving rise to the observed CDC, we constructed a stochastic computational model simulating a transition from an undifferentiated to a differentiated state (Fig. 3A). The model simulates microwells that initially start with $N_{0}$ undifferentiated cells. Cells stochastically proliferate and die at experimentally obtained rates ((32), see Fig S8, S9, and supplementary text for a detailed explanation of model construction). We assumed in the model that division and death rates were identical for differentiated and undifferentiated cells, as delaying the division time of differentiated cells (consistent with the slower division observed for CD62 $\mathrm{L}^{+}$cells, Fig S2, (33)) did not have a pronounced effect on the simulation outcome (Fig S10). Cells in the model differentiate by some rate $R$, which can be either constant ( $R=$ constant, red line in Fig. 3A) or collective (i.e. dependent on $N$, the instantaneous number of cells in the microwell $(R=$ collective, blue line in Fig. 3A)). As we showed that differentiation in our system depended on cell number, we assumed that $R_{\text {collective }}(N)$ has the same functional form as the CDC, and used a logistic curve to describe it in the model. The three parameters that describe $R_{\text {collective }}(N)$ (namely $M, r$, and $N c$ ), were thus extracted from the fit to the experimental CDC (Fig. 2J). We scanned the parameters of the logistic curve, and found 
that the experimentally derived parameters that we used for the simulations were inside a broad optimal region in parameter space (Fig. S9A-B), justifying their use without fitting. This allowed us to run simulations with all model parameters obtained directly from experimental observations.

We then calculated the simulated fraction of differentiated cells at $96 \mathrm{~h}$ for different values of $N_{0}$, for both differentiation regimes (constant and collective), and compared with the measured distributions of $\mathrm{CD}_{2} \mathrm{~L}^{+}$and $\mathrm{CD} 44^{+}$(Fig. 3B). Simulations assuming collective differentiation fit the CD62 $\mathrm{L}^{+}$data well over all values of $N_{0}$ (Fig. 3B, top), much better than simulations of a model based on a constant differentiation rate (Fig. S9C). A model assuming a constant differentiation rate, however, fit $\mathrm{CD} 44^{+}$data but not that of $\mathrm{CD} 62 \mathrm{~L}^{+}$ (Fig. 3B, bottom). Of note, $T c$ and $A c$ obtained by the simulation resembled the experimentally derived values, with the collective and constant differentiation rates showing behavior similar to that of CD62L and CD44, respectively (Figure S11). The stochastic simulation with collective differentiation also captured the well-to-well variability of the experimental data (Fig. 3C) as well as the experimentally observed dynamic changes in the average numbers of both $\mathrm{CD}^{2} 2 \mathrm{~L}^{+}$and $\mathrm{CD} 62 \mathrm{~L}^{-}$cells, and their dependence on $N_{0}$ (Fig. 3D-E, Table S3). A model in which cell differentiation depends on the number of neighbors only at the beginning of the experiment, rather than continuously changing with cell number, is less consistent with our data (Fig. S11D-E). We verified experimentally that differentiation remains plastic by transferring $\mathrm{T}$ cells into microwells at varying times after their activation in bulk culture, and showing that differentiation outcome depended on the new number of neighbors (Fig. S12). Thus, a stochastic model for cell differentiation can describe the experimentally observed collectivity if the differentiation rate $R$ depends on the instantaneous number of interacting cells as described by the logistic CDC, with differentiation significantly increasing above $N c \sim 30$ interacting T cells.

\section{The cytokines IL-2 and IL-6 and the transmembrane protein SLAMF6 modulate collective differentiation}

Finally, we sought to identify candidate signaling molecules and pathways that facilitated the observed local collectivity. Short-range interactions between T cells within the same 
microwell can be mediated by cell-surface ligands and their receptors, as well as by secreted cytokines, which accumulate at high concentrations in the vicinity of the cells and sharply decline with distance $(34,35)$. Thus, we repeated our microwell array experiments, while adding antibodies to block specific cytokines or surface molecules, or using cells from knock-out mouse strains that lacked relevant genes. Out of the several candidate cytokines and genes that we tested, three showed a significant effect on CD62L expression (Fig. S13 and Table S2). The inhibition of the cytokines interlukin-2 (IL-2) and interlukin6 (IL-6) using blocking antibodies reduced CD62L expression after $96 \mathrm{~h}$ of culture (Fig. 4A), whereas the absence of the cell-surface molecule SLAMF6 (Slamf6-1- cells) enhanced its expression (Fig. 4B). We note that blocking IL-2 strongly reduced cell numbers in the microwells at late time points (Fig. S14A). To overcome this difficulty, IL-6 was added to increase cell viability (Fig 4C and Fig. S14A, (29)), without altering CD62L expression (Fig. 4A, C). Adding back external human IL-2 increased CD62L expression in a concentration-dependent way (Figs. S13, S14).

Further evidence for the involvement of IL-2 and IL-6 in driving collective differentiation was revealed from investigation of their signaling pathways. We found that in clustering cells, the receptor subunits IL-2R $\alpha$ and IL-6Rst were non-uniformly distributed on the cell surface, and displayed patches which were typically directed towards neighboring cells within the cluster (Fig. 4D and S15B-C). IL-2 is expressed and secreted by activated T cells at early time points (Fig. S15A, (26)), and is directed towards T-T synapses (27). We verified that IL-6 was also produced by T cells in our cultures early after activation (Fig. S15A), though we could not infer its localization due to low signal. The polarization of cytokine receptors toward neighboring cells together with accumulation of cytokines within T-cell clusters (23) may lead to increased signaling capacity. Supporting this hypothesis, we observed that the phosphorylation of STAT5 and STAT3 in response to IL2 or IL-6, respectively, was significantly higher when cells were cultured at high density, thus forming more clusters (Fig. 4E and S16). Finally, we observed that JAK inhibitors, which block STAT signaling downstream of IL-2 and IL-6, reduced CD62L expression and pTCM formation, whereas PI3K pathway inhibition, which is also activated by IL-2 signaling, did not (Fig. 4F). 


\section{Collective differentiation curve analysis and model simulations reveal that IL-2 and IL-6 modulate collective pTCM formation distinctly, and orthogonal to their effect on cell proliferation}

The CDC derived for each of these perturbations provided a faithful and compact description of the differentiation trajectory, allowing us to assess the net effect on collective cell differentiation, regardless of the effect on cell proliferation and survival. The results recapitulated our previous observations, as blocking IL-2 or IL-6 resulted in reduced CD62 $\mathrm{L}^{M A X}$ values, while in the absence of SLAMF6, CD62 $\mathrm{L}^{M A X}$ was increased around Nc (Fig 5A, and Table S2). The CDC further showed that when IL-2 is blocked but the culture is supplemented with IL-6, CD62L expression remained low even in microwells in which substantial number of cells has accumulated $(N>N c)$ (Fig 4C and Fig. 5A, left). Addition of human IL-2 restored the CDC to its unperturbed form in a concentration dependent manner (Fig. S13B and Table S2).

The different perturbations can be described by their effect on the parameters of the logistic curve that fits the perturbed CDC. Blocking IL-2 reduced the maximum responsiveness (given by the parameter $M$ ), which is consistent with IL-2 regulating the probability of a cell to differentiate at a given number of neighbors (Fig. 5A, left). In contrast, blocking IL6 only marginally decreased $M$, but shifted the CDC curve to higher cell numbers (Fig. 5A, middle). This is consistent with IL-6 playing a role in decreasing $N c$, the critical number of interacting cells that promotes differentiation. The surface molecule SLAMF6 had the opposite effect, as its absence somewhat reduced $N c$ but did not change $M$ (Figure 5A, right). We cannot preclude an additional effect of IL-2 also on $N c$ with the current data. The effects of these perturbations on the CDC can be captured by the stochastic computational model. Changing only the parameter $M$ in $R_{\text {collective }}$ resulted in simulated trajectories that resemble those obtained by blocking IL-2, and also captured the gradual recovery of differentiation that is observed when adding back external IL-2 (Fig. 5B, left, Fig. 5C, bottom). Simulating reduced proliferation (which is caused by IL-2 blockade) cannot describe the experimentally observed distributions or the CDC if $M$ is unchanged (Fig 5C,D). The experimentally observed behavior for anti-IL-6 and SLAMF6 knockout conditions can be described by changing the parameter $N c$ in the model (Fig. 5B, middle and right panels). These results demonstrate that the three factors affect collective CD62L 
expression, orthogonal to their effect on cell proliferation and survival: IL-2 regulates the maximal differentiation rate, whereas IL-6 and SLAMF6 tune the critical number of cells required for differentiation.

\section{Discussion}

In this work, we systematically analyzed the role that intercellular interactions between CD4 $\mathrm{T}$ cells play in central $\mathrm{T}$ cell memory formation. By activating $\mathrm{T}$ cells in a synthetic microenvironment, we showed that local cell density can modulate the balance between $\mathrm{CD}_{62} \mathrm{~L}^{+}$and CD62 $\mathrm{L}^{-}$cells, independent of further potential influence by antigen presenting cells or TCR signaling strength. Using this system we were able to determine that differentiation into memory precursors is most efficient at $\mathrm{N}>\sim 30$ interacting cells, and that this collective property depends on the instantaneous number of interacting cells, rather than on the number of division cycles the cells undergo.

The signals which direct $\mathrm{T}$ cell memory development have been studied extensively and several models of $\mathrm{T}$ cell diversification have been suggested $(11,36)$. Hence, TCR stimulation strength (37) and duration (38), as well as signaling by various cytokines (11), have been shown to modulate the generation and maintenance of memory $\mathrm{T}$ cells. Our results support the notion that local, short-range interactions between $\mathrm{T}$ cells early after TCR stimulation serve as another potent modulator of memory induction. Depending on the experimental model, local collectivity might influence differentiation to memory or effector phenotypes, depending on the number of precursor cells which participate in the response and their extent of proliferation.

Our findings further suggest that the cytokines IL-2 and IL-6, which are expressed by T cells just a few hours after TCR stimulation, are mediators of local collectivity. The surface protein SLAMF6 also affected collective memory formation, although to a lower extent. IL-2 (39), as well as IL-6 (40) has been previously shown to promote T cell memory differentiation. We found that IL-2 is required for collective pTCM generation at the early stage of the response ( $<3$ days). We note that IL-2 may have other effects at later time points, for example at the peak of in vivo responses $(41,42)$, or during the contraction phase and maintenance of memory cells (41), which, together with other cytokines such as 
IL-15 and IL-7, can further modulate the long-term magnitude of the memory response. We also provided data which suggest that IL-2 and IL-6 contribute to collectivity in the generation of pTCM at least in part by increased sensitivity of clustered T cells to IL-2 and IL-6. Interestingly, IL-6 (40), as well as members of the SLAMF family of surface receptors (43), have been shown to enhance the IL-2 sensitivity of CD4 T cells. Antibodies blocking the adhesion molecule LFA-1 affect memory formation in vivo (44), but we did not observe a significant effect in our cultures (Fig. S13, Table S2). This may stem from interactions of $\mathrm{T}$ cells with other cells in vivo, which are lacking in our ex vivo cultures. The formation of T-cell memory is a highly complex process and we expect that other molecular components, which we have not yet identified, may contribute to the phenomenon of density-dependent cellular cooperation we have described.

We hypothesize that the property of increased memory formation above a threshold of locally interacting cells can have a functional role, as it may prioritize the allocation of immune memory to insults that result in large responses, while preventing aberrant memory of potentially less relevant small events. Local collectivity can also impact on the diversity of immune memory, by tuning interactions between $\mathrm{T}$ cell clones of different TCR specificities that interact during priming, for example through clustering on the same antigen presenting cell. Understanding the rules of $\mathrm{T}$ cell social behavior will be important in order to learn how to manipulate the immune system for therapeutic or prophylactic goals.

\section{Materials and Methods}

$\underline{\text { Mice }}$

C57BL/6, B6SJL and TCR-transgenic OT-II mice (harboring ovalbumin (OVA)specific $\mathrm{CD}^{+} \mathrm{T}$ cells), were housed under specific pathogen free conditions at the animal facility of Weizmann Institute and were used at 6-8 weeks of age. SLAMF6 deficient mice $\left(\right.$ Slamf6 $\left.^{--}\right)(45)$ were a kind donation from the laboratory of Prof. Idit Shachar from the Weizmann Institute of Science. All animal experiments were performed under protocols approved by the Animal Care and Use Committee of the Weizmann Institute.

$\underline{\text { Adoptive transfer }}$ 
For experiment detailed in Figure 1A: At day -1, naïve OT-II cells (expressing anti-CD45.1 on a C57BL/6 background) were injected into C57BL/6 recipients. Either $10^{3}$ or $10^{5}$ cells per mouse were injected i.v. On day zero, mice were immunized i.p. with $100 \mu$ PBS containing $50 \mu \mathrm{g}$ Albumin protein (Sigma-Aldrich) together with alum as an adjuvant (diluted 1:3, ThermoFisher Scientific). On day five, total cells were isolated from recipient spleens and labeled with anti CD45.1-APC-Cye7, CD45.2-AlexaFluor-488, CD3-PE and CD4-PrCp-Cy5.5 to assess the fraction of donor cells out of recipient $\mathrm{CD} 4^{+} \mathrm{T}$ cells. Cells were also stained with anti CD62L-APC and CD44-PE-Cy7 to analyze their differentiated state.

For the experiment detailed in Figure 1F; naïve $\mathrm{CD}^{+}{ }^{+} \mathrm{T}$ cells were isolated from B6SJL mice (expressing CD45.1 on a C57BL/6 background) and cultured in low and high initial concentrations $\left(6.25 * 10^{4}\right.$ and $2 * 10^{6}$ cells $/ \mathrm{ml}$ respectively). Cells were activated using anti-CD3/CD28 micro-beads and cultured in 6-well plates for $72 \mathrm{~h}$. At the end of the culture period, dead cells were removed on a Ficoll gradient and either $1 * 10^{6}$ or $2 * 10^{6}$ (depending on the experiment) donor cells were injected i.v. to C57BL/6 recipients. At three time points (3, 4 and $>35$ days), total cells were isolated from recipient spleens. Cells were labeled with anti-CD45.1-APC-Cye7, CD45.2-AlexaFluor-488, CD3-PE and CD4PacificBlue to assess the fraction of donor cells out of recipient $\mathrm{CD}^{+} \mathrm{T}$ cells. Cells were also stained with anti CD62L-APC, CD44-PE-Cy7, KLRG1-PrCp-Cy5.5 and CD27BrillientViolet510 to analyze their differentiation state. For antibody specifications see Table S4.

\section{$\underline{\text { Bulk cell culture }}$}

Naïve $\mathrm{CD} 4^{+} \mathrm{T}$ cells were purified from mice spleens using magnetic microbeads separation $\left(\mathrm{CD} 4{ }^{+} \mathrm{CD} 62 \mathrm{~L}^{+} \mathrm{MACS} \mathrm{T}-\mathrm{cell}\right.$ Isolation Kit, Miltenyi Biotec). Unless stated otherwise, cells were cultured in 96-well plates in $200 \mu \mathrm{l}$ of RPMI. Cells were seeded at varying concentrations indicated in the main text, and activated either with anti-CD3 and antiCD28-coated micro-beads at a 1:1 bead:cell ratio (Dynabeads, Invitrogen) or in the presence of $2 \mu \mathrm{l} / \mathrm{ml}$ cell activation cocktail (PMA + ionomycin, Biolegend). For the experiment presented in Figure 1C (top), naïve OT-II cells were used and activated using $10 \mu \mathrm{g} / \mathrm{ml}$ OVA peptide (SQAVHAAHAEINEAGR, InvivoGen) presented by pre-loaded 
dendritic cells (1:1 OTII:DC ratio). Cells were cultured in complete RPMI 1640 medium with phenol red, supplemented with $10 \%$ (vol/vol) fetal calf serum (FCS), $100 \mathrm{U} / \mathrm{ml}$ of penicillin, $100 \mathrm{mg} / \mathrm{ml}$ of streptomycin, $2 \mathrm{mM}$ glutamine, $10 \mathrm{mM}$ HEPES, $1 \mathrm{mM}$ sodium pyruvate, and $50 \mathrm{mM} \beta$-mercaptoethanol, all from Biological Industries (Beit Haemek, Israel). Whenever cultured for flow cytometry measurements, cells were stained with the proliferation dye eFluor-450 (ebioscience) prior to the start of culture: after isolation, cells were supplemented with $1 \mathrm{ml}$ of PBS $+1 \mu 1$ eFluor-450, incubated for $10 \mathrm{~min}$ at $37^{\circ} \mathrm{C}$ and then washed three times with RPMI.

\section{Extracellular markers flow cytometry sample preparation}

Cells were harvested at the different time points indicated in the text (typically at $t=0,24$, 48, and $72 \mathrm{~h}$ ), placed in a u-shaped 96 well plate and washed twice with PBS. The supernatant was aspirated and cells were supplemented with live-dead blue reagent (Invitrogen) diluted 1:1000 in PBS, to a final volume of $20 \mu 1$. Samples were then supplemented with $5 \mu 1$ antibody mix: anti-CD62L-PE-Cy7, CD44-APC-Cy7, CD4-FITC, CD69-PE and IL2Ra-APC ( $0.25 \mu 1 /$ sample for each antibody), to a final volume of $25 \mu 1$ (for antibody specification see Table S4). Samples were then incubated in the dark for 30 min at room temperature, washed twice with BPS and measured using a flow cytometer (LSRII; BD).

\section{Microwell array design and fabrication}

Photolithography masks were designed using autoCAD (Autodesk, San Rafael, CA). Molds were designed as an array of several hundreds of hexagonally spaced micro-wells each being $80 \mu \mathrm{m}$ in diameter and $120 \mu \mathrm{m}$ in depth. This depth is $12-20$ times cell diameter, thus reducing escape of activated cells. Microwell preparation is described in detail in Zaretsky et al.(30). In brief, molds were fabricated using photolithography of negative photoresist on silicon wafers. In a slight alteration from the cited protocol, photoresist spinning was performed twice yielding feature heights of $120 \mu \mathrm{m}$. Wafers were exposed to UV irradiation on a contact mask aligner using a dark-field mask, hardened, and treated to remove un-bound photoresist. PDMS was mixed in 10:1 weight ratio (base:curing agent). One milliliter was then poured on the template wafer and spun (WS-650S spin processor, Laurell Technologies) for $30 \mathrm{sec}$ at $300 \mathrm{rpm}$ followed by $2 \mathrm{~min}$ at $1000 \mathrm{rpm}$. Wafers were 
then left to stand for 10 min to even the PDMS surface and then baked for 1 hour at $80^{\circ} \mathrm{C}$ until PDMS was fully cured. After curing, the thin PDMS layer was cut into stripes, peeled and gently placed on strips of a thick PDMS slice. This thick PDMS was used to help place the thin layer containing the array into a 96-well. Small squares $(\sim 5 \mathrm{~mm}$ by $5 \mathrm{~mm})$ containing the micro-well pattern were cut and punched into an optical bottom 96-well plate (Thermo Fisher Scientific, Rochester, NY) using tweezers. As the thin layer adhered strongly to the bottom of the plate, it detached from the thick layer and remained inside the 96-well plate.

\section{Cell loading and culture in microwell arrays}

For all microscopy experiments, naïve $\mathrm{CD} 4^{+} \mathrm{T}$ cells were purified from mice spleens using magnetic microbead negative separation (Naïve CD4+ isolation, StemCell Technologies). Cells were cultured in medium identical to that used for bulk culture, but without phenol red. For all microscopy experiments, activating microbeads were used at a 1:1 bead:cell ratio. To facilitate cell loading into the small-volume microwells and eliminate trapped air bubbles that remained in the microwells due to the hydrophobicity of PDMS, wells were filled with $200 \mu \mathrm{l}$ of culture medium and the plate was placed in vacuum for 1 hour followed by 1 min centrifugation at $300 \mathrm{xg}$ to remove residual bubbles. The plate was then left at $4^{\circ} \mathrm{C}$ overnight. Cells were loaded into the microwell array, followed by loading of the activation micro-beads. First, the medium was removed and replaced with $12.5 * 10^{3}$ primary naïve T cells in $100 \mu 1$ of culture medium. The plate was centrifuged at $300 \mathrm{x} g$ for $1 \mathrm{~min}$ to allow cells to settle. Residual cells were aspirated and $100 \mu \mathrm{l}$ of medium containing activation micro-beads was loaded into the wells. Beads were left to settle for 5 min after which the medium was aspirated and replaced with $100 \mu$ of fresh tissue culture medium without phenol red as indicated. This seeding procedure gave an average cell number of $4.7 \pm 2.6$ and average bead number of $8.5 \pm 4.5$ (Fig. S5A). Then, wells were loaded with $100 \mu \mathrm{l}$ of culture medium supplemented with a combination of anti CD44FITC, CD62L-PE and CD45.2-APC antibodies in a dilution of $1: 5 * 10^{3}, 1: 10^{4}$ and 1:10 respectively. This gave a final culture volume of $200 \mu 1$ with twice the listed antibody dilution. For antibody specification, see Table S4.

\section{$\underline{\text { Perturbation in microwells }}$}


Whenever antibodies were used, microwells were supplemented with $100 \mu 1$ of culture medium containing fluorescent antibodies as indicated above, and $100 \mu 1$ of culture medium containing the blocking antibodies at double the final concentration. Final antibody concentrations were: anti-IL-2 $(10 \mu \mathrm{g} / \mathrm{ml})$, anti-IL-6 $(10 \mu \mathrm{g} / \mathrm{ml})$, anti-IL-15/15R $(5 \mu \mathrm{g} / \mathrm{ml})$ and anti-IL-6Ra $(5 \mu \mathrm{g} / \mathrm{ml})$. IL-6 and recombinant human-IL-2 (both from R\&D) were given at final concentrations of $20 \mathrm{ng} / \mathrm{ml}$ for IL-6 and 0.1 or $10 \mathrm{ng} / \mathrm{ml}$ for human-IL2.

When anti-LFA-1 and ICAM-1 were used, microwells were pre-coated with the reagent to interfere with cell-cell adhesion. For anti-LFA-1, microwells we pre-coated with $20 \mu \mathrm{g} / \mathrm{ml}$ of the antibody in PBS over night at $4^{\circ} \mathrm{C}$. ICAM- 1 coating was performed in two steps. First microwells were coated with protein A to enable correct positioning of the ICAM-1 molecules, and then coated with ICAM-1/Fc chimera protein (R\&D): $20 \mu \mathrm{g} / \mathrm{ml}$ of Protein A was diluted in PBS (+calcium +magnesium) supplemented with $1 \mathrm{mM} \mathrm{NaHCO}_{3}$. Seventy microliters of the mix were added to the microwells and incubated for 2 hours at $37^{\circ} \mathrm{C}$. Protein A solution was aspirated and replaced with $70 \mu \mathrm{l}$ of blocking buffer (PBS supplemented with 2\% Human Serum Albumin, Calbiochem) followed by a $10 \mathrm{~min}$ incubation at room temperature. Finally, ICAM-1 was diluted in blocking buffer to 20 $\mu \mathrm{g} / \mathrm{ml}$ and $70 \mu \mathrm{l}$ was added to the microwells and incubated over night at $4^{\circ} \mathrm{C}$. Wells were washed with culture medium before cell seeding.

\section{Live-cell imaging acquisition}

For time-lapse experiments, a Ti-eclipse microscope (Nikon Instruments) was used equipped with an automated stage, incubator, and a closed chamber that allowed for $\mathrm{CO}_{2}$ flow over the 96-well plate. Cells were imaged using 20x/NA $=0.17$ objective (sFlour, Nickon) and monitored using bright field illumination and three fluorescence channels: FITC, Cy3 and Cy5. Time-lapse movies were collected using the Andor software. Cells were images every two to six hours, depending on the experiment, using an Andor iXon888 EMCCD camera (1024 x 1024 pixels, $13 \mu \mathrm{m}$ pixel size).

\section{Confocal microscopy imaging}

Naïve CD4 cells were cultured at a concentration of $10^{6}$ cells $/ \mathrm{ml}$ in 24-well plates, and in the presence of $2 \mu \mathrm{l} / \mathrm{ml}$ Cell Activation Cocktail (PMA + ionomycin, Biolegend). After 24 
hours, paraformaldehyde (PFA, Biolegend) was added directly to the cells to a final concentration of $1.6 \%$, and cells were incubated for 15 minutes at room temperature in the dark. To keep clusters intact, washing of the cells was performed gently on the culture dish by adding staining buffer (PBS $+4 \%$ FCS) and removing it several times. Cells were supplemented with $500 \mu 1$ of staining buffer with $5 \mu 1$ anti-IL-6st-PE and $5 \mu 1$ antiIL-2RaAlexa-Fluor-488 and incubated for 30 minutes at room temperature in the dark. Cells were washed with PBS and seeded on a 6-well plate with a glass bottom. Cells were imaged using Fv3000 laser scanning confocal microscope (Olympus) using PLAPON 60x OSC2 super-corrected objective with 1.4 NA, at a sampling speed of $2 \mu \mathrm{s} /$ pixel.

\section{PI3K and JAK/STAT inhibition}

Naïve $\mathrm{CD}^{+} \mathrm{T}$ cells were cultured in three initial cell numbers as indicated in the text for 72 h. At the culture start time, small-molecule inhibitors for PI3K (LY-294002, Sigma) and JAK/STAT (AZ-1480, Sellechem) were added to separate cultures at a concentration of $5 \mu \mathrm{M}$ each. After $72 \mathrm{~h}$, cells were labeled as described above and measured using flow cytometry.

\section{Pospho-STAT sample preparation}

Protocol of pSTAT measurements was adopted from Feinerman et al (46). For pSTAT5 measurements, naïve CD4 T cells where cultured in 24-well plates at a cell concentration of $1 * 10^{6}$ cells $/ \mathrm{ml}$ with activation micro-beads ( $1: 1 \mathrm{bead}: c e l l$ ratio) and in the presence of anti-IL-2 $(10 \mu \mathrm{g} / \mathrm{ml})$ to prevent endogenous IL-2 binding. After $24 \mathrm{~h}$, unclustered and clustered cells were separated using a $10 \mu \mathrm{m}$ mesh (PlutiSelect) using the following steps: the mesh was washed with culture medium from both sides. Cells were washed and supplemented with $500 \mu \mathrm{l}$ of fresh medium and (without mixing) passed through the mesh into a one well on a 24-well plate, this contained the unclustered cells. The mesh was washed 3x with $500 \mu 1$ of medium, flipped onto a second well, and washed from its other side with $500 \mu 1$ medium. This well contained the clustered cells (see Fig. S16A for images of clustered and unclustered cells). Each fraction was supplemented with $500 \mu 1$ of culture medium with $1 \mu \mathrm{l}$ live-dead blue reagent and either with or without $5 \mathrm{ng} / \mathrm{ml}$ human-IL-2. The culture plate was incubated for $10 \mathrm{~min}$ at $37^{\circ} \mathrm{C}$ and immediately supplemented with PFA (Biolegend) in a final concentration of 1.6\%. Cells were incubated in the dark for 15 
min at room temp and then washed at $600 \mathrm{xg}$. The supernatant was aspirated and replaced with $1 \mathrm{ml}$ of $90 \%$ ice cold methanol followed by a 30 min incubation on ice in the dark. After incubation, cells were washed with staining buffer (PBS $+4 \%$ FCS), and supplemented with $90 \mu 1$ of stain buffer and $10 \mu 1$ of stain mix containing: $5 \mu 1$ of antipSTAT5-FITC (ebioscience), $1 \mu 1$ anti-IL-2Ra-PerCp-Cy5.5, $1 \mu 1$ anti-CD4-PE and $3 \mu 1$ stain buffer. Cells were incubated in room temperature for $30 \mathrm{~min}$ in the dark, washed twice with stain buffer and measured on the flow cytometer (LSRII; BD). For pSTAT3 measurements, cells were cultured in two initial concentrations - either $1 * 10^{6}$ or $6.25 *$ $10^{4}$ cells $/ \mathrm{ml}$. After $24 \mathrm{~h}$ cells were washed once and supplemented with $200 \mu 1$ RPMI either with or without $10 \mathrm{ng} / \mathrm{ml}$ of IL-6. Cell fixation and staining was performed as described above for pSTAT5.

\section{Imaging Flow Cytometry (ImageStream) sample preparation and analysis}

Naïve cells were cultured in $24-$ well plates at a concentration of $10^{6}$ cells $/ \mathrm{ml}$ with activation micro-beads ( $1: 1$ bead:cell ratio). After $72 \mathrm{~h}$ of culture, cells were collected into $5 \mathrm{ml}$ tubes and washed with PBS. Supernatant was aspirated and replaced with $100 \mu 1$ PBS with $10 \mu \mathrm{M}$ Hoechst 33342 (life technologies) and with anti CD45.2-AlexaFluor488, IL2Ra-APC, and CD3-PE (1 $\mu$ l each). Cells were incubated at room temperature in the dark for $30 \mathrm{~min}$, washed once with PBS, transferred to 1.5-ml tubes (Eppendorf) and centrifuged at $400 \mathrm{xg}$. Supernatant was gently aspirated using a $10-\mathrm{ml}$ syringe and samples were supplemented with PBS to a final volume of $50 \mu$ l. Samples were measured using multispectral Imaging Flow Cytometry (ImageStreamX mark II; Amnis Corp, part of EMD millipore, Seattle, WA). Imaging was performed using 60x/NA $=0.9$ lens; the lasers used were $405 \mathrm{~nm}$ (120 mW) for Hoechst, $488 \mathrm{~nm}$ (100 mW), $561 \mathrm{~nm}(200 \mathrm{~mW}), 642 \mathrm{~nm}(150$ $\mathrm{mW})$, and $785 \mathrm{~nm}(5 \mathrm{~mW})$ for side scatter (SSC) channel imaging. At least $5 * 10^{4}$ cells were collected from each sample and data were analyzed using image analysis software (IDEAS 6.2; Amnis Corp). Cells were gated for single cells or doublets using the area and aspect ratio features, and for focused cells using the Gradient RMS feature. $\mathrm{CD} 3{ }^{+} \mathrm{CD} 25^{+}$ cells were gated, and the relative concentration of the cell-cell synapse was calculated. First, a mask was created to delineate the cell synapse, using the VALLEY mask (rectangular mask that sits between two bright regions, such as between two nuclei. This minimum intensity identifies the intersection between the two objects) dilated for 3 pixels, 
based on the nuclear Hoechst staining. We calculated the intensity concentration ratio feature (the ratio of the intensity inside the first input mask to the intensity of the union of the two masks), the higher the score, the greater the concentration of intensity inside the first mask. The ratio is mapped to a log scale based on the Valley mask.

\section{RNA sequencing}

For CD62L $\mathrm{L}^{+/-}$cell sorting (described in Fig. 1D-E), naïve CD4+ cells were cultured for 48 and 72 hours at a concentration of $2.5 * 10^{5}$ cells $/ \mathrm{ml}$ and activated using microbeads as described above. This cell concentration was selected to yield a relatively similar fraction of $\mathrm{CD}_{62} \mathrm{~L}^{+}$and $\mathrm{CD} 62 \mathrm{~L}^{-}$cells at the indicated time points. At each time point $\mathrm{CD} 4{ }^{+} \mathrm{CD} 62 \mathrm{~L}^{+}$ cells were sorted into $100 \mu 1$ of Lysis/Binding buffer (Invitrogen). For comparison between the transcriptome of cells cultured in high and low concentrations (Fig. S7), naïve CD4 cells were cultured in 24-well plates ( $1 \mathrm{ml} /$ well) for 18, 30, 48, and 72 hours at a starting concentration of either $10^{6}$ or $6.25 * 10^{4}$ cells $/ \mathrm{ml}$. At the indicated time points, live CD4 ${ }^{+}$ cells were sorted into $100 \mu 1$ of Lysis/Binding buffer. Additionally, naïve CD4 ${ }^{+}$cells were cultured for 48 and 72 hours at a concentration of $2.5 * 10^{5}$ cells $/ \mathrm{ml}$ and sorted for $\mathrm{CD} 4{ }^{+} \mathrm{CD} 44^{+} \mathrm{CD} 62 \mathrm{~L}^{+}$and $\mathrm{CD} 4{ }^{+} \mathrm{CD} 44^{+} \mathrm{CD} 62 \mathrm{~L}^{-}$populations at the indicated times.

Total RNA was extracted with poly-dT beads (Dynabeads, Invitrogen). We used a variation of the MARS-seq protocol (47) developed to produce single cell RNA-seq libraries. In brief, the protocol consists of special designed primers with unique molecular identifiers (UMI) for accurate molecule counting and a step of linear amplification of the initial mRNA pool, followed by a library construction step. This way, the diversity of the original pool of messenger RNAs is preserved even if the amount of input RNA is low. Three replicate libraries were prepared for each of the different populations. First, the samples were incubated at $72^{\circ} \mathrm{C}$ for $3 \mathrm{~min}$ and immediately transferred to $4^{\circ} \mathrm{C}$. Then, $2 \mu \mathrm{l}$ of an RT reaction mix (10 mM DTT, $4 \mathrm{mM}$ dNTP, $2.5 \mathrm{U} / \mu 1$ Superscript III RT enzyme in $50 \mathrm{mM}$ Tris- $\mathrm{HCl}$ ( $\mathrm{pH} 8.3$ ), $75 \mathrm{mM} \mathrm{KCl,} 3 \mathrm{mM} \mathrm{MgCl}$ ) were added into each well. The samples were then spun down and incubated as follows: $2 \mathrm{~min}$ at $42^{\circ} \mathrm{C}, 50 \mathrm{~min}$ at $50^{\circ} \mathrm{C}$, and $5 \mathrm{~min}$ at $85^{\circ} \mathrm{C}$. Indexed samples with equivalent amount of cDNA were pooled. The pooled cDNA was converted to double-stranded DNA with a second strand synthesis kit (NEB) in a $20 \mu 1$ reaction, incubating for $2.5 \mathrm{~h}$ at $16^{\circ} \mathrm{C}$. The product was purified with $1.4 \mathrm{x}$ volumes 
of SPRI beads, eluted in $8 \mu \mathrm{l}$ and in vitro transcribed (with the beads) at $37^{\circ} \mathrm{C}$ overnight for linear amplification using the T7 High Yield RNA polymerase IVT kit (NEB). Following IVT, the DNA template was removed with Turbo DNase I (Ambion) 15 min at $37^{\circ} \mathrm{C}$ and the amplified RNA (aRNA) purified with $1.2 \mathrm{x}$ volumes of SPRI beads. RNA was chemically fragmented (median size $\sim 200$ nucleotides) by incubating for 3 min at $70^{\circ} \mathrm{C}$ in Zn2+ RNA fragmentation solution (Ambion) and purified with two volumes of SPRI beads. Next, a partial Illumina Read1 sequencing adapter that includes a pool barcode was single strand ligated to the fragmented RNA using a T4 RNA ligase I (New England Biolabs): The RNA $(5 \mu \mathrm{l})$ was pre incubated 3 min at $70^{\circ} \mathrm{C}$ with $1 \mu 1$ of $100 \mu \mathrm{M}$ ligation adapter. Then, $14 \mu \mathrm{l}$ of a mix containing 9.5\% DMSO, $1 \mathrm{mM}$ ATP, 20\% PEG8000 and 1 $\mathrm{U} / \mu 1 \mathrm{~T} 4$ ligase in $50 \mathrm{mM}$ Tris $\mathrm{HCl} \mathrm{pH7.5,10} \mathrm{mM} \mathrm{MgCl} 2$ and $1 \mathrm{mM}$ DTT was added. The reaction was incubated at $22^{\circ} \mathrm{C}$ for $2 \mathrm{~h}$. The ligated product was reverse transcribed using Affinity Script RT enzyme (Agilent) and a primer complementary to the ligated adapter: The reaction was incubated for $2 \mathrm{~min}$ at $42^{\circ} \mathrm{C}, 45 \mathrm{~min}$ at $50^{\circ} \mathrm{C}$ and $5 \mathrm{~min}$ at $85^{\circ} \mathrm{C}$. cDNA was purified with $1.5 \mathrm{x}$ volumes of SPRI beads. The library was completed and amplified through a nested PCR reaction with $0.5 \mu \mathrm{M}$ of P5_Rd1 and P7_Rd2 primers and PCR ready mix (Kapa Biosystems): The forward primer contains the Illumina P5-Read1 sequences and the reverse primer contains the P7-Read 2 sequences. The amplified pooled library was purified with $0.7 \mathrm{x}$ volumes of SPRI beads to remove primer leftovers. Library concentration was measured by a Qubit fluorometer (Life Technologies) and mean molecule size was determined by TapeStation (Agilent). DNA libraries were sequenced on an Illumina NextSeq 500 with an average of approximately $1 * 10^{6}$ aligned reads per sample.

\section{Quantitative-PCR}

Naïve CD4 T cells were isolated and $3 * 10^{5}$ naïve cells were transferred to $1.5 \mathrm{ml}$ tubes (Eppendorf), washed once with PBS, supplemented with $1 \mathrm{ml}$ Tri-reagent (Sigma) and immediately frozen in $-80^{\circ} \mathrm{C}$, for subsequent RNA extraction (naïve sample). The remaining cells were cultured in $24-$ well plates at a concentration of $10^{6}$ cells $/ \mathrm{ml}$ and activated using microbeads. At 8 and $24 \mathrm{~h}$, cells were detached from the activation microbeads by $5-$ min incubation in culture medium containing $5 \mathrm{mM}$ EDTA. Then, cells 
were placed on a magnet for $3 \mathrm{~min}$ and the cell fraction was transferred to $1.5-\mathrm{ml}$ tubes. Cells were washed (450 $\mathrm{x} g$ for $10 \mathrm{~min}$ ) supplemented with $1 \mathrm{ml}$ of tri-reagent and frozen. Total RNA was isolated according to the manufacturer's protocol (Life Technologies). The total RNA was reverse-transcribed into cDNA using M-MLV RT primed with oligo(dT) primers (Promega). Real-time PCR was performed using the Fast SYBR ${ }^{\mathrm{TM}}$ Green master mix in the Quant Studio 5 machine (Applied Biosystems). See Table S5 for primer specifications. Primer amplification efficiency and specificity were verified for each set of primers at a final concentration of $250 \mathrm{nM}$. The determined amounts of cDNA template were $4 \mathrm{ng}$ for Hprt and Il2 and $32 \mathrm{ng}$ for Il6. mRNA expression levels of the tested genes relative to Hprt were calculated using the $\Delta \Delta \mathrm{Ct}$ method, using the naïve sample as a reference.

\section{References and notes}

We thank Prof. I. Shachar and L. Radomir for their help with Slamf6-/- mice and useful discussions; Prof. R. Alon and Dr. S. Feigelson for their help with ICAM-1 coating protocol and productive conversations. T. Bigdari for the design of the graphical abstract and N. David for help with the illustrations.

\section{Funding}

NF research was supported by the Israel Science Foundation (grant no. 1184/15) and by a grant from the Israel Ministry of Science, Technology and Space and the German Cancer Research Center (DKFZ). NF is Incumbent of The Eugene and Marcia Appelbaum Professorial Chair. NF and $\mathrm{BC}$ were supported by a grant from the WeizmannUK foundation. BC is supported by a Weston Visting Professorship from the Weizmann Institute of Science.

\section{Author contribution}

M.P. was involved in the design and implementation of all experiments and computer simulations, performed downstream and statistical analysis, generated the figures and wrote the manuscript. J.R. was involved in implementation of image analysis algorithms 
and provided initial insights for this study. A.K.P. constructed the stochastic simulations. I.Z. conducted adoptive transfer experiments. S.M conducted quantitative-PCR experiments. C.B constructed cDNA libraries and conducted RNA-seq. E.D, N.K and G.S. were involved in downstream analysis of RNA-seq data. Z. P. conducted image-stream analysis. B.C and N.F designed experiments, supervised all stages of the project, and wrote the manuscript.

\section{Competing interests}

The authors declare no competing interests

\section{Data availability}

MATLAB code used for single cell stochastic simulations, including additional parameters which are required for the run, can be downloaded through GitHub: https://github.com/innate2adaptive/Single-cell-imaging.

RNAseq data is available at **

\section{References:}

1. V. R. Buchholz et al., Disparate individual fates compose robust CD8+ T cell immunity. Science. 340, 630-5 (2013).

2. P. D. Hodgkin, M. R. Dowling, K. R. Duffy, Why the immune system takes its chances with randomness. Nat. Rev. Immunol. 14, 711 (2014).

3. C. J. Wellard, G. T. Belz, A. M. Lew, M. R. Dowling, Antigen affinity, costimulation, and cytokine inputs sum linearly to amplify $\mathrm{T}$ cell expansion. Science (80-. ). 346, 1123-1128 (2014).

4. C. R. Plumlee, B. S. Sheridan, B. B. Cicek, L. Lefrançois, Environmental Cues Dictate the Fate of Individual CD8+ T Cells Responding to Infection. Immunity. 39, 347-356 (2013).

5. S. L. Reiner, W. C. Adams, Lymphocyte fate specification as a deterministic but highly plastic process. Nat. Rev. Immunol. 14, 699-704 (2014).

6. J. T. Chang et al., Asymmetric T lymphocyte division in the initiation of adaptive immune responses. Science. 315, 1687-1691 (2007).

7. J. Arsenio et al., Early specification of CD8+ T lymphocyte fates during adaptive immunity revealed by single-cell gene-expression analyses. Nat. Immunol. 15, 365-72 (2014).

8. A. L. Marzo et al., Initial T cell frequency dictates memory CD8+ T cell lineage commitment. Nat. Immunol. 6, 793-799 (2005). 
9. V. P. Badovinac, J. S. Haring, J. T. Harty, Initial T Cell Receptor Transgenic Cell Precursor Frequency Dictates Critical Aspects of the CD8+ T Cell Response to Infection. Immunity. 26, 827-841 (2007).

10. J. J. Obar, K. M. Khanna, L. Lefrançois, Endogenous Naive CD8+ T Cell Precursor Frequency Regulates Primary and Memory Responses to Infection. Immunity. 28, 859-869 (2008).

11. A. Lanzavecchia, F. Sallusto, Understanding the generation and function of memory T cell subsets. Curr. Opin. Immunol. 17, 326-332 (2005).

12. F. Sallusto, D. Lenig, R. Förster, M. Lipp, a Lanzavecchia, Two subsets of memory T lymphocytes with distinct homing potentials and effector functions. Nature. 401, 708-712 (1999).

13. S. M. Kaech et al., Selective expression of the interleukin 7 receptor identifies effector CD8 T cells that give rise to long-lived memory cells. Nat. Immunol. 4, 1191-1198 (2003).

14. R. M. Kondrack et al., Interleukin 7 Regulates the Survival and Generation of Memory CD4 Cells. J. Exp. Med. 198, 1797-1806 (2003).

15. J. Li, G. Huston, S. L. Swain, IL-7 Promotes the Transition of CD4 Effectors to Persistent Memory Cells. J. Exp. Med. 198, 1807-1815 (2003).

16. J. J. Obar, L. Lefrancois, Memory CD8+ T cell differentiation. Ann N Y Acad Sci. 1183, 251-266 (2010).

17. J. A. Best et al., Transcriptional insights into the CD8 $+\mathrm{T}$ cell response to infection and memory T cell formation. Nat. Immunol. 14, 404-412 (2013).

18. B. Youngblood, J. S. Hale, R. Ahmed, Memory CD8 T cell transcriptional plasticity. F1000Prime Rep. 7, 38 (2015).

19. C. M. Carlson et al., Kruppel-like factor 2 regulates thymocyte and T-cell migration. Nature. 442, 299-302 (2006).

20. H. Ichii et al., Bcl6 is essential for the generation of long-term memory CD4+ T cells. Int. Immunol. 19, 427-433 (2007).

21. A. Banerjee et al., Cutting edge: The transcription factor eomesodermin enables CD8+ T cells to compete for the memory cell niche. J. Immunol. 185, 4988-92 (2010).

22. Dang, Dang, Xiaojiong Lu, Yuefen Lou, FOXO1 Up-Regulates Human L-selectin Expression Through Binding to a Consensus FOXO1 Motif. Gene Regul. Syst. Bio., 139 (2012).

23. K. Holzerova, J. Zurmanova, J. Neckar, F. Kolar, O. Novakova, Early transcriptional and epigenetic regulation of $\mathrm{CD} 8+\mathrm{T}$ cell differentiation revealed by single-cell RNA-seq. Nat. Immunol., 1-34 (2017).

24. M. a Cannarile et al., Transcriptional regulator Id2 mediates CD8+ T cell immunity. Nat. Immunol. 7, 1317-1325 (2006).

25. F. Masson et al., Id2-mediated inhibition of E2A represses memory CD8+ T cell differentiation. J. Immunol. 190, 4585-94 (2013). 
26. B. Hoffman, D. a Liebermann, Apoptotic signaling by c-MYC. Oncogene. 27, 6462-72 (2008).

27. O. Cazzalini, a I. Scovassi, M. Savio, L. a Stivala, E. Prosperi, Multiple roles of the cell cycle inhibitor p21(CDKN1A) in the DNA damage response. Mutat. Res. 704, 12-20 (2010).

28. S. M. Kaech, W. Cui, Transcriptional control of effector and memory CD8+ T cell differentiation. Nat. Rev. Immunol. 12, 749-761 (2012).

29. S. Adutler-Lieber et al., Substrate-bound CCL21 and ICAM1 combined with soluble IL-6 collectively augment the expansion of antigen-speci fi c murine CD4 1 T cells. Blood Adv. 1, 1016-1030 (2017).

30. I. Zaretsky et al., Monitoring the dynamics of primary $\mathrm{T}$ cell activation and differentiation using long term live cell imaging in microwell arrays. Lab Chip. 12, 5007-15 (2012).

31. M. Polonsky, B. Chain, N. Friedman, Clonal expansion under the microscope: studying lymphocyte activation and differentiation using live-cell imaging. Immunol. Cell Biol., 1-8 (2015).

32. E. D. Hawkins, M. L. Turner, M. R. Dowling, C. van Gend, P. D. Hodgkin, A model of immune regulation as a consequence of randomized lymphocyte division and death times. Proc. Natl. Acad. Sci. U. S. A. 104, 5032-7 (2007).

33. I. Kinjyo et al., Real-time tracking of cell cycle progression during CD8+ effector and memory T-cell differentiation. Nat. Commun. 6, 6301 (2015).

34. K. Thurley, D. Gerecht, E. Friedmann, T. Höfer, Three-dimensional gradients of cytokine signaling between T cells. PLoS Comput. Biol. 11, 1-22 (2015).

35. Z. Liu et al., Immune homeostasis enforced by co-localized effector and regulatory T cells. Nature. 528, 225-30 (2015).

36. R. Ahmed, M. J. Bevan, S. L. Reiner, D. T. Fearon, The precursors of memory: Models and controversies. Nat. Rev. Immunol. 9, 662-668 (2009).

37. A. V. Gett, F. Sallusto, A. Lanzavecchia, J. Geginat, T cell fitness determined by signal strength. Nat. Immunol. 4, 355-360 (2003).

38. M. a. Williams, M. J. Bevan, Shortening the Infectious Period Does Not Alter Expansion of CD8 T Cells but Diminishes Their Capacity to Differentiate into Memory Cells. J. Immunol. 173, 6694-6702 (2004).

39. H. Dooms, K. Wolslegel, P. Lin, A. K. Abbas, Interleukin- 2 enhances CD4 ${ }^{+}$T cell memory by promoting the generation of IL-7R $\alpha$-expressing cells. J. Exp. Med. 204, 547-557 (2007).

40. S. a. Nish et al., T cell-intrinsic role of IL-6 signaling in primary and memory responses. Elife. 2014, 1-21 (2014).

41. D. M. Mitchell, E. V. Ravkov, M. a. Williams, Distinct Roles for IL-2 and IL-15 in the Differentiation and Survival of CD8+ Effector and Memory T Cells. $J$.

Immunol. 184, 6719-6730 (2010).

42. K. K. Mckinstry et al., Effector CD4 T-cell transition to memory requires late 
cognate interactions that induce autocrine IL-2. Nat Commun. 5, 1-12 (2014).

43. D. Comte et al., Engagement of SLAMF3 enhances CD4 + T-cell sensitivity to IL2 and favors regulatory T-cell polarization in systemic lupus erythematosus. Proc. Natl. Acad. Sci. 113, 9321-9326 (2016).

44. A. Gérard et al., Secondary T cell-T cell synaptic interactions drive the differentiation of protective CD8+ T cells. Nat. Immunol. 14, 356-363 (2013).

45. F. Zhao, J. L. Cannons, M. Dutta, G. M. Griffiths, P. L. Schwartzberg, Positive and Negative Signaling through SLAM Receptors Regulate Synapse Organization and Thresholds of Cytolysis. Immunity. 36, 1003-1016 (2012).

46. O. Feinerman et al., Single-cell quantification of IL-2 response by effector and regulatory T cells reveals critical plasticity in immune response. Mol. Syst. Biol. 6, 1-16 (2010).

47. J. P. Meador et al., Massively Parallel Single-Cell RNA-Seq for Marker-Free Decomposition of Tissues into Cell Types. Science (80-. ). (2014), doi:10.1126/science.1247651.

\section{Figure legends:}

\section{Figure 0: Collective local interactions enhance $\mathrm{CD4}^{+}$memory $\mathrm{T}$ cell differentiation.}

The effects of intercellular interactions on $\mathrm{T}$ cell memory formation were studied in microwell arrays, each well holding a different number of locally interacting cells. Proliferation and differentiation were evaluated using time-lapse movies, over 4 days. Differentiation into memory precursors sharply increases above a threshold number of interacting cells. This is modulated by increased sensitivity of the interacting cells to the cytokines IL-2 and IL-6. Figure curtesy of Tal Bigdari, Division of Research Services, Weizmann Institute of Science

\section{Figure 1: Differentiation of pTCM cells is modulated by $\mathbf{T}$ cell number in vivo and in} vitro. A) Either $10^{3}$ or $10^{5}$ OT-II TCR transgenic CD4 T cells (CD45.1) were transferred into C57BL/6 recipients (CD45.2), which were then immunized with Albumin protein together with an adjuvant (alum). Five days after immunization, the fractions of pTCM $\left(\mathrm{CD} 44^{+} \mathrm{CD} 6 \mathrm{~L}^{+}\right)$and $\mathrm{pTEM}\left(\mathrm{CD} 44^{+} \mathrm{CD} 62 \mathrm{~L}^{-}\right)$cells were evaluated in the population of transferred cells. Results are representative of two mice out of nine in one experiment. Mean \pm SD values are indicated for each population. B) The percentage of pTCM cells in 
mice injected with either $10^{3}(\mathrm{n}=4)$ or $10^{5}(\mathrm{n}=5)$ OT-II cells, five days following immunization. Filled squares: mean. P-value was calculated using a two-sided Student's $t$-test $(* *, \mathrm{P}<0.01) . \mathrm{C})$ The percentage of $\mathrm{pTCM}$ cells measured at $72 \mathrm{~h}$ in cultures of $\mathrm{CD}^{+}$ naïve $\mathrm{T}$ cells cultured ex vivo at the indicated densities, and activated either with OVA presenting dendritic cells (top, $\mathrm{n}=6$ samples in one experiment) or with activation microbeads coated with anti-CD3 / anti-CD28 antibodies (bottom, $\mathrm{n}=3$ samples from one representative experiment out of three). Filled squares: mean. P-values were calculated using 1-way ANOVA with $\mathrm{P}<0.01$ in both cases (see Table S1). D) The expression levels, measured by RNA-seq, of selected gene transcripts in $\mathrm{CD}^{+}{ }^{+} \mathrm{T}$ cells sorted into $\mathrm{CD}^{2} 2 \mathrm{~L}^{+}$ and CD62 $\mathrm{L}^{-}$populations after $72 \mathrm{~h}$ of culture. Cell were cultured at an initial cell number of $2.5 * 10^{5}$ cells / well and activated using anti-CD3 / anti-CD28 antibodies. E) Gene ontology (GO) enrichment analysis of differentially expressed genes in the CD62 $\mathrm{L}^{+}$and CD62L' subpopulations. Differentially expressed genes $(\mathrm{P} \leq 0.05$, Benjamini-Hochberg correction), with $\log -2$ fold change of $\geq 0.5$ between $\mathrm{CD}^{2} 2 \mathrm{~L}^{+}$and $\mathrm{CD} 62 \mathrm{~L}^{-}$samples were chosen for the analysis. Results are from $n=3$ repeats. F) Naïve $\mathrm{CD}^{+} \mathrm{T}$ cells were cultured ex vivo for $72 \mathrm{~h}$ in either high $\left(2 * 10^{6}\right.$ cells $\left./ \mathrm{ml}\right)$ or low $\left(6.25 * 10^{4}\right.$ cells $\left./ \mathrm{ml}\right)$ initial densities, activated using anti-CD3 / anti-CD28-coated beads, and then transferred into CD45.2 recipients (total of 40 mice in two individual experiments). Spleens were harvested from recipient mice after 3, 14, 35 or 48 days (depending on the experiment). The fraction of donor cells was evaluated out of the total $\mathrm{CD}^{+} \mathrm{CD}^{+}$cells in recipient spleens. The recovery of cells pre-cultured in high (filled) or low (empty) concentrations were compared. Fold-change values (High / Low) are indicated in parenthesis. Data are shown for all mice from the two individual experiments. Filled squares: mean values. P-values were calculated using a two sided Student's $t$-test $(*, \mathrm{P}<0.05 ; * *, \mathrm{P}<0.01$; ***, $\mathrm{P}<$ $0.001)$.

\section{Figure 2: Induction of CD62L expression depends on local interactions between} differentiating $\mathbf{T}$ cells. An array of micro-wells was placed on the bottom of an optical 96-well plate. Naïve CD4 T cells and activation micro-beads were seeded such that the microwells randomly received a different initial number of cells $\left(N_{0}\right)$. Cells in different microwells shared culture medium. Dynamic quantification of CD44 and CD62L 
expression levels was achieved by fluorescently labeled antibodies added to the culture medium at $\mathrm{t}=0 \mathrm{~h}$ at a very low concentration (see materials and methods). A) Top: schematics of the experiment, microwell array side view. T cells and activation microbeads (black dots) are shown. Representative image strips show microwells with $N_{0}=1$ (top three rows) and $N_{0}=8$ (bottom three rows). Cells were imaged for $96 \mathrm{~h}$ using bright-field illumination (BF), and 2 fluorescent channels (CD44, red; CD62L, yellow). Numbers on top show time in $\mathrm{h}$. Scale bar $=20 \mu \mathrm{m}$. B) Time traces of all microwells in one representative experiment out of three $(n=674$ microwells) showing the fraction of $\mathrm{CD} 2 \mathrm{~L}^{+}$(top) and CD44+ (bottom) in each microwell over $96 \mathrm{~h}$. Microwells are grouped by $N_{0}\left(1 \leq N_{0} \leq 10\right.$ initial cells). Color code represents the fraction of positive cells in each microwell. C) Fraction of CD62 $\mathrm{L}^{+}$(top) and $\mathrm{CD}_{4} 4^{+}$(bottom) cells after $72 \mathrm{~h}$ of culture, plotted versus $N_{0}$. Each gray dot represents one microwell, black squares represent median values. Data is from the same experiment as in B. D) Representative area traces from microwells starting with $N_{0}=4$ cells. The average trace is depicted in color. All traces are normalized by their initial area. E) Average cell area traces for microwells starting with different $N_{0}$ values. Each trace is normalized by its initial cell area. Data is combined from three experiments ( $\mathrm{n}=1,734$ microwells). F) Critical area $(A c)$, defined as the area in which $50 \%$ of the cells are differentiated $\left(\mathrm{CD}_{2} 2 \mathrm{~L}^{+}\right)$, plotted versus $N_{0}$ for all microwells in three experiments as in E. G) Critical time (Tc), defined as the time in which $50 \%$ of the cells have differentiated, plotted versus $N_{0}$ as in F. H) Traces of two representative microwells starting with one (blue) or four (red) initial cells. Top: fraction of CD62 $\mathrm{L}^{+}$over time; Bottom: cell area over time. $T c$ and $A c$ are indicated by the dotted lines. I) Fraction of $\mathrm{CD}_{2} \mathrm{~L}^{+}$plotted as a function of cell area for the two microwells shown in $\mathrm{H}$. J) Derivation of the collective differentiation curve (CDC). Left: The frequency distribution of all microwells from all time points in one representative experiment plotted on the area$\mathrm{CD}_{2} \mathrm{~L}^{+}$plane; right: the CDC is defined by the maxima of the heatmap on the left, binned by cell area. Data for CDC derivation was averaged over eight individual experiments (blue squares). Error bars show SEM. The obtained CDC was fitted with a logistic curve (line), of the form: $F(N)=M /\left(1-e^{\left(-r\left(N-N_{C}\right)\right.}\right) ; \mathrm{R}^{2}=0.99$. 
Figure 3: CD62L expression dynamics can be simulated by assuming collective differentiation. A) A stochastic agent-based model of the differentiation process. Cells can proliferate, differentiate, and die. The proliferation rates $\left(P^{\prime}\right.$, first division; $P$, subsequent divisions) and death rate $(D)$ were experimentally obtained from single cell data, as detailed in the supplementary information section. We assume in the model identical rates for un-differentiated and differentiated cells. The differentiation rate, $R$, can be either constant ( $R_{\text {constant }}$, red line), or have a logistic dependence on the number of cells in a microwell $\left(R_{\text {collective }}\right.$, blue curve, $R(N)=M /\left(1-e^{\left(-r\left(N-N_{C}\right)\right)}\right)$. B) Distributions of the fraction of $\mathrm{CD}_{2} \mathrm{~L}^{+}$(top) and $\mathrm{CD}_{4} 4^{+}$(bottom) cells after $96 \mathrm{~h}$ for microwells starting with varying $N_{0}$ values. Experimental data (gray) compared to simulations assuming $R_{\text {constant }}$ (red) or $R_{\text {collective }}$ (blue). Data is combined from three experiments as in Figure 2. The parameters used for $R_{\text {collective }}$ were obtained from fitting the CDC of Figure $2 \mathrm{~J}$ ( $M=$ $0.95, r=0.25$ and $N c=30$ ). $R_{\text {constant }}=0.15$ gave best fit to the $\mathrm{CD}_{4} 4^{+}$data. $\mathrm{C}$ ) The relative expansion of $\mathrm{CD} 2 \mathrm{~L}^{+}$cells over time, showing experimentally obtained (left) and simulated (right) traces, of microwells starting with $N_{0}=4$ cells. Colored trace shows mean values. Data is from the same experiments as in B. D) The average expansion of CD62L $\mathrm{L}^{+}$ cells for experimentally obtained (left) or simulated (right) data, for microwells with different values of $N_{0}$. E) Same as is D, showing average expansion of CD62 L' cells.

Figure 4: IL-2, IL-6 and SLAMF6 modulate CD62L expression. A-B) Histograms showing the mean expression levels of CD62L (given as mean fluorescent intensity (MFI)) in all microwells from two independent experiments, comparing different perturbations (colored-shaded) to the control ("No Ab.", gray-shaded). MFI values were calculated at $t$ $=96 \mathrm{~h}$. A) Left: microwells supplemented with $10 \mu \mathrm{g} / \mathrm{ml}$ of anti-IL-2 together with 20 $\mu \mathrm{g} / \mathrm{ml}$ of IL-6, which was added to increase cell viability (“+ $+\alpha \mathrm{IL}-2+\mathrm{IL}-6$ (20)", $\mathrm{n}=789$ ). Middle: microwells supplemented with $20 \mathrm{ng} / \mathrm{ml}$ of IL-6 (“+IL-6(20)”, n = 863). Right: microwells supplemented with $10 \mu \mathrm{g} / \mathrm{ml}$ anti-IL6 ("+ $+\alpha \mathrm{IL}-6 ", \mathrm{n}=1605)$. All three plots show the control sample from the same experiment $(n=812)$. B) MFI of microwells harboring Slamf6 ${ }^{-/}$cells $(n=686)$ compared to control cells $(n=645)$. C) Representative images of control microwells ('No Ab.') or microwells treated with anti-IL-2 $(10 \mu \mathrm{g} / \mathrm{ml})$ supplemented with IL-6 $(20 \mathrm{ng} / \mathrm{ml})$. Images were taken at $\mathrm{t}=54 \mathrm{~h}$ of culture. Images show 
bright-field illumination (BF, top), CD62L (middle) and CD44 (bottom). Scale bar $=20$ $\mu \mathrm{m}$. D) Confocal images of a T-cell cluster after $24 \mathrm{~h}$ of activation using PMA + ionomycin, showing IL-6 receptor (IL-6st), IL-2Ra (CD25) and nuclei (DNA). Images are maximum projection over the total $\mathrm{z}$ stack. Scale bar $=20 \mu \mathrm{m}$. E) IL-2 and IL-6 downstream signaling of clustered (filled circles) and un-clustered (open circles) cells (for pSTAT5, see also Fig. S16), or for cells cultured in dense (filled circles) or sparse (empty circles) cultures (for pSTAT3). Percentage of $\mathrm{pSTAT}^{+}$cells (left) and $\mathrm{pSTAT}^{+}$cells (right) were measured by flow cytometry after $24 \mathrm{~h}$ of culture followed by a 10-min pulse of $5 \mathrm{ng} / \mathrm{ml}$ of IL-2 (left) or $10 \mathrm{ng} / \mathrm{ml}$ of IL-6 (right). IL-2 data is pooled from three individual experiments with a total of $n=13$ samples for each condition. IL- 6 data is from one experiment with $n=4$ repeats for each condition. F) Small-molecule inhibition of the JAK/STAT and the PI3K pathways. Cells were cultured at the indicated initial cell numbers with either PI3K (empty circles) or JAK/STAT (black circles) small-molecule inhibitors, or without inhibition (gray circles). The percentage of pTCM cells was measured using flow cytometry $72 \mathrm{~h}$ after activation. Data were averaged from $n=4$ wells each, for low and intermediate initial cell numbers ( 1.25 and $5 * 10^{4}$, respectively) and from $\mathrm{n}=3$ wells for the high cell number $\left(40 * 10^{4}\right)$. Data are from one representative experiment out of three. In E-F, Mean \pm SD are shown. P-values were calculated using a two sided Student's $t$-test $(*, \mathrm{P}<0.05 ; * *, \mathrm{P}<0.01 ; * * *, \mathrm{P}<0.001)$. $\mathrm{P}$-values in $\mathrm{F}$ compare STAT inhibition to the control.

Figure 5. CDC analysis and stochastic simulations show distinct effects of IL-2 and IL-6 on collective differentiation, orthogonal to their effect on $\mathbf{T}$ cell proliferation A) CDC plots for the experimental perturbations shown in figure 4, compared to control ("No $\mathrm{Ab}$ ", grey, averaged over eight individual experiments). The experimental CDCs (squares) were obtained by averaging data from all experiments for each condition (as given below), and were fitted using a logistic function (line). Left: addition of $10 \mu \mathrm{g} / \mathrm{ml}$ of anti-IL-2 supplemented with $0.1 \mathrm{ng} / \mathrm{ml}$ human-IL-2 ("+ $+\alpha \mathrm{IL}-2+$ hIL-2(0.1)", orange, $\mathrm{n}=3$ experiments) or with $20 \mathrm{ng} / \mathrm{ml}$ of IL-6, (" $+\alpha \mathrm{IL} 2+$ IL-6 (20)", green, $\mathrm{n}=2$ experiments).

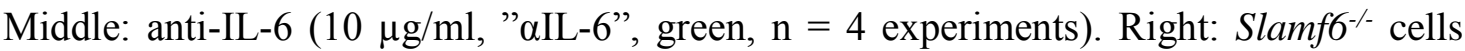
(green, $\mathrm{n}=2$ experiments). B) CDCs obtained by model simulations using modified 
$R_{\text {collective }}$ parameters. Control CDC (gray) was constructed from the output of a simulation assuming collective differentiation with nominal values as in Figure $3(M=0.95, N c=30)$. Modified parameters that were used: left: Changing the maximal differentiation rate: $M=$ 0.2 (orange) or 0.05 (green); middle: Changing the critical cell number: $N c=38$; right: $N c$ $=20$. C) Distributions of the fraction of $\mathrm{CD}_{2} \mathrm{~L}^{+}$cells after $96 \mathrm{~h}$, for microwells starting with varying $N_{o}$ values and supplemented with $10 \mu \mathrm{g} / \mathrm{ml}$ of anti-IL-2 and $0.1 \mathrm{ng} / \mathrm{ml}$ of hIL2, as in A-left. Experimental data (gray) were compared to simulations assuming collective differentiation as in Figure 3B. As inhibition of IL-2 also inhibits proliferation, the data was compared to a simulation in which the division time of the cells was extended. Top: division time is unchanged ("1x"); middle: division is 3 times slower (“3x"); bottom: division time is unchanged and $M$ is reduces $(M=0.2)$. D) CDC curves of simulation results (squares) for the corresponding conditions in C. Simulation results with the nominal parameter values (1x, as in Fig. 3) were fitted with a logistic curve, which is shown in all three graphs as a reference.

\section{Supplementary material}

Supplementary text

Figure S1 - S16

Tables S1 - S5

Movie S1

Supplementary references $(48-50)$ 
Transfered cells: $10^{3}$

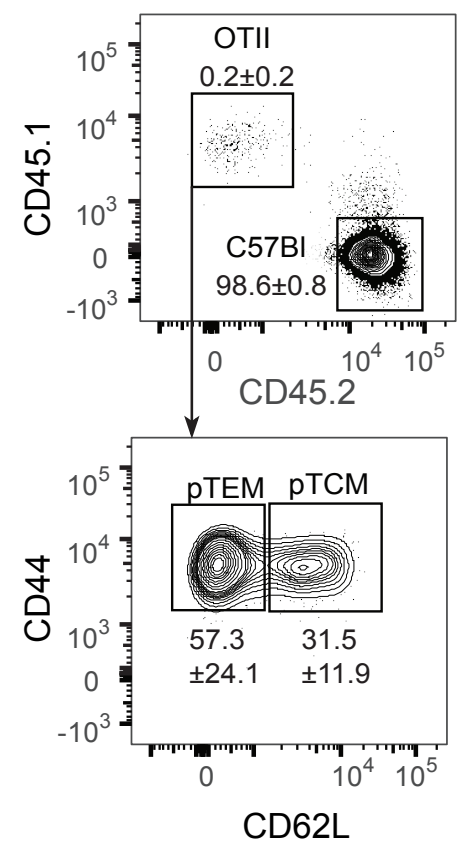

D

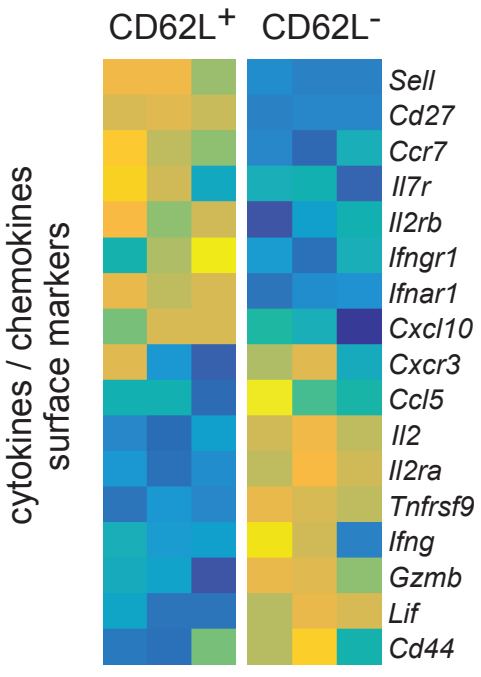

$10^{5}$
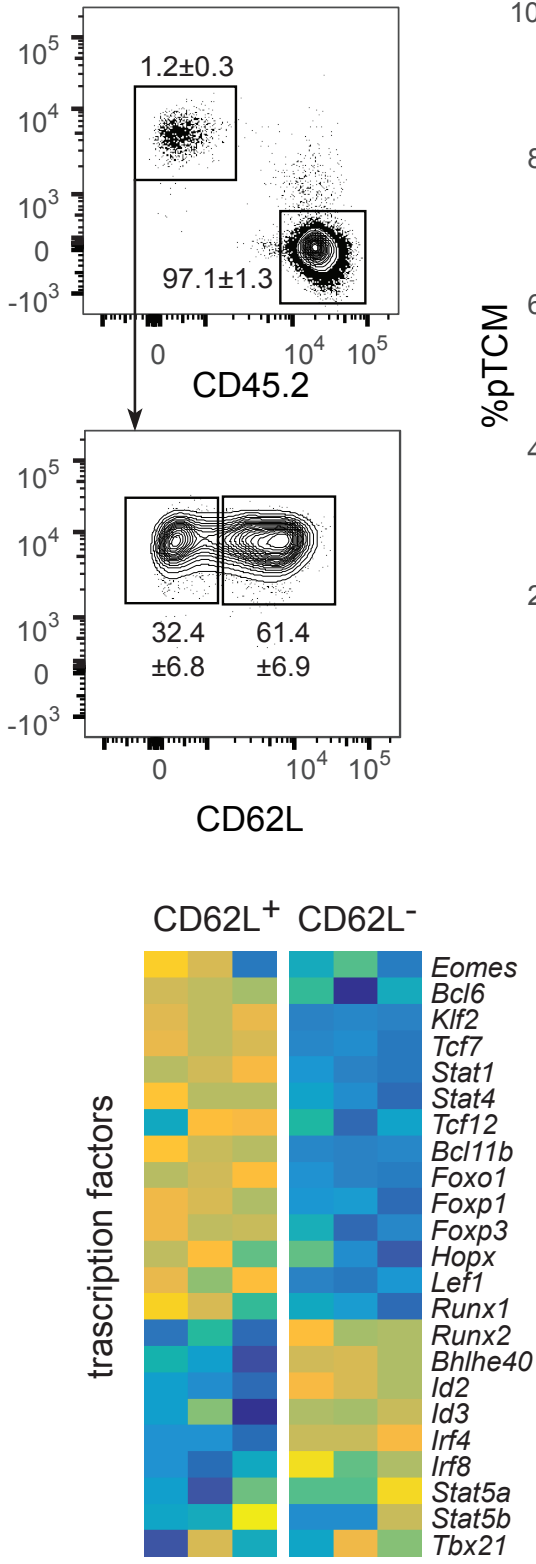

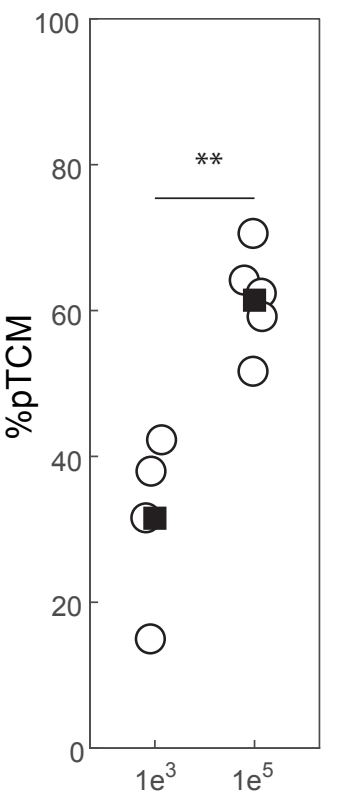

Transfered cells
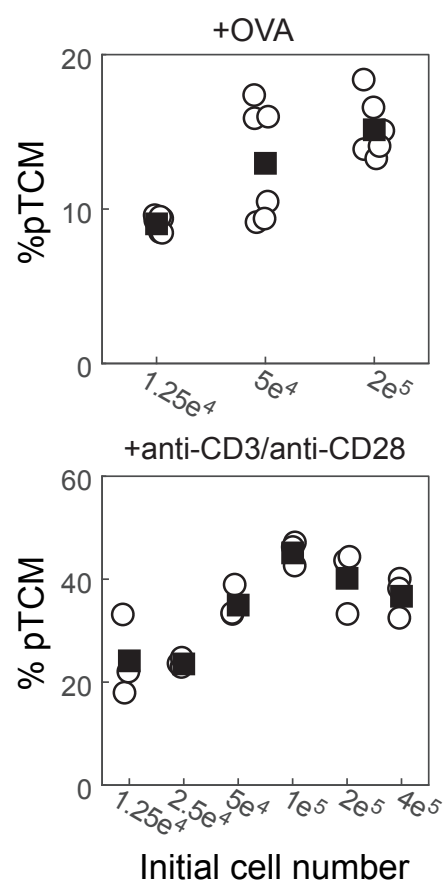

E

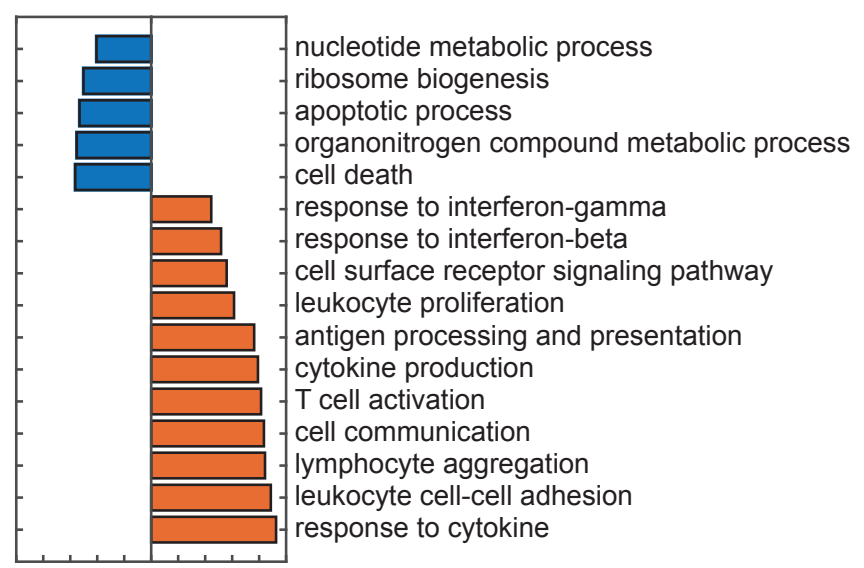

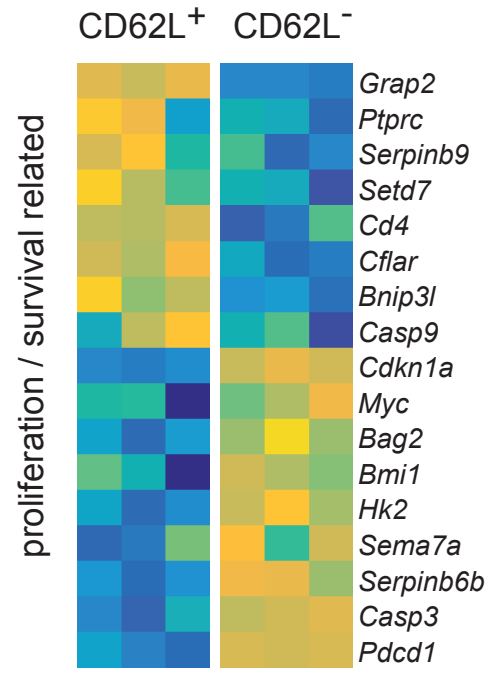
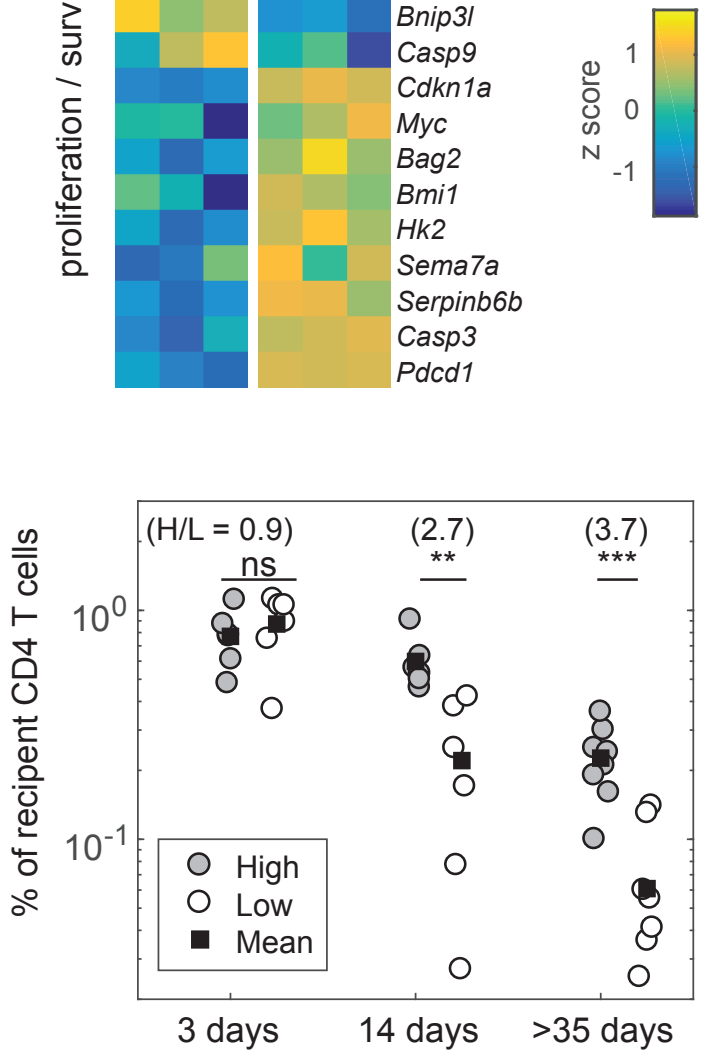
A
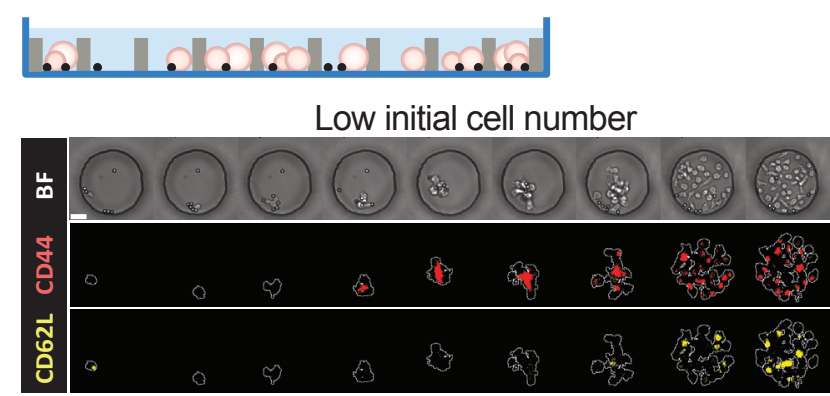

$\mathrm{N}_{0}=1$

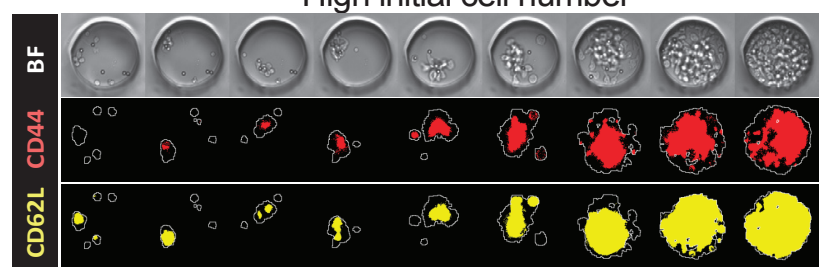

$\mathrm{N}_{0}=8$

D

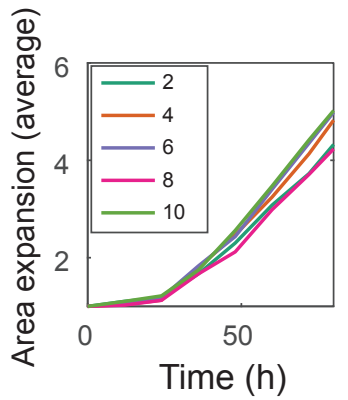

$\mathrm{H}$
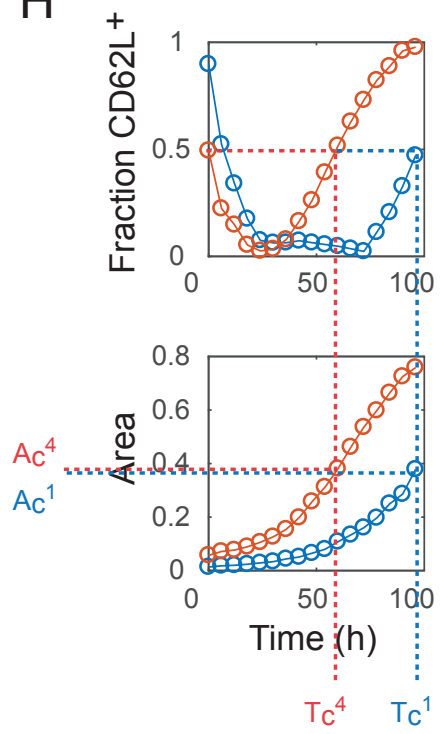

E
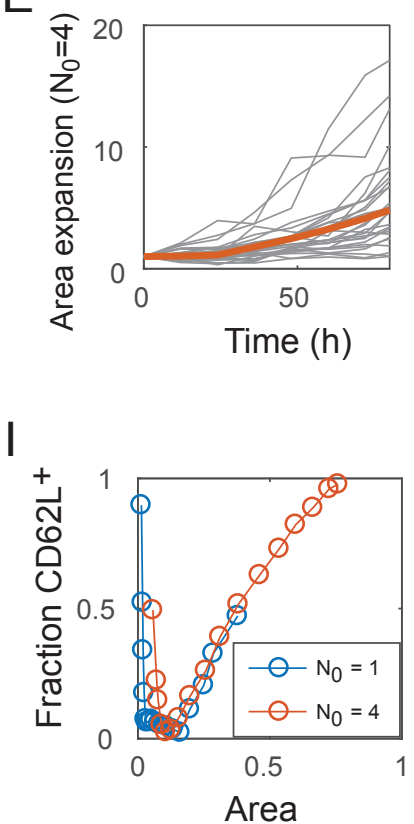

B
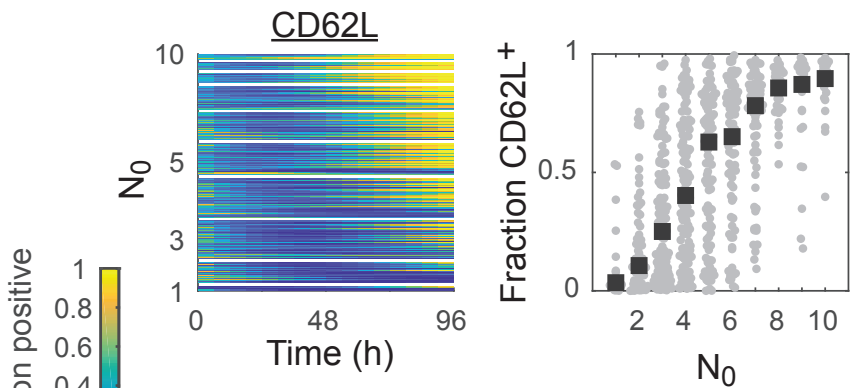

$\begin{array}{cc}\text { 음 } & 0.4 \\ \text { 는 } & 0.2 \\ \text { ㄴ } & 0\end{array}$

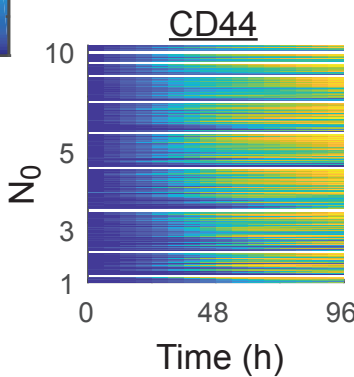

F

C

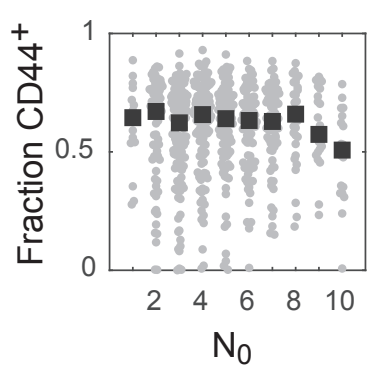

G
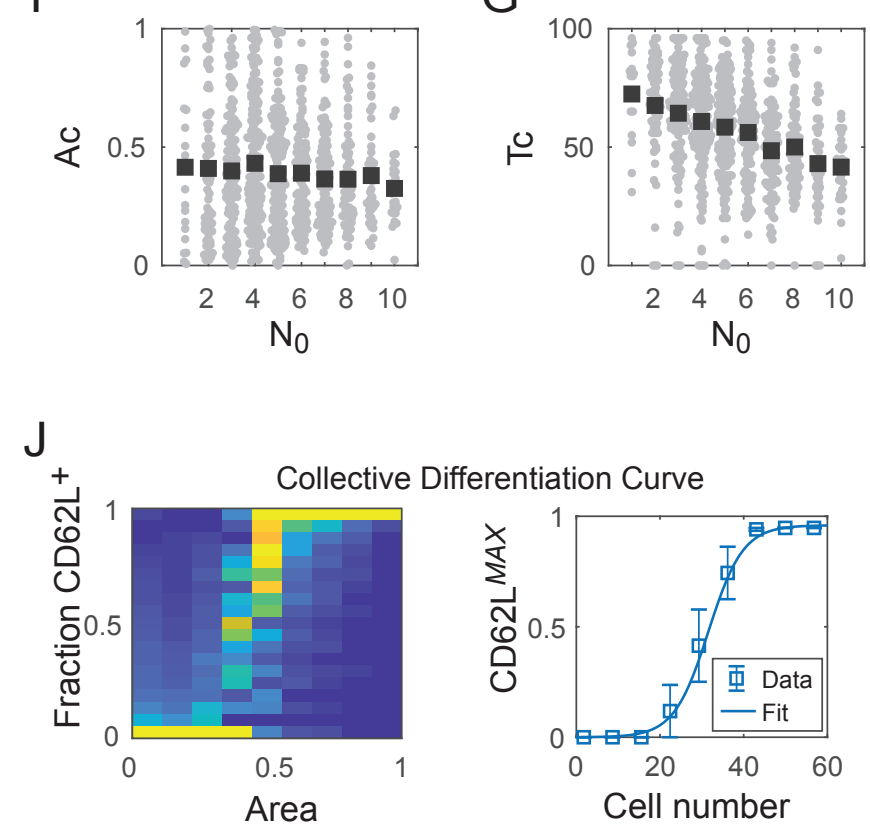

$\begin{array}{llllll}0 & 0.2 & 0.4 & 0.6 & 0.8 & 1\end{array}$

Fraction of wells

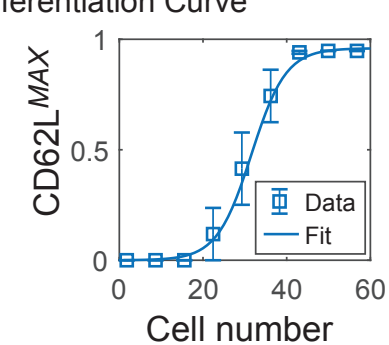

(estimated from area) 
A

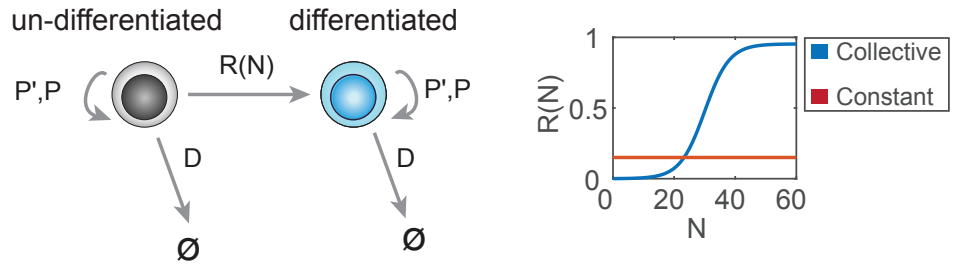

B

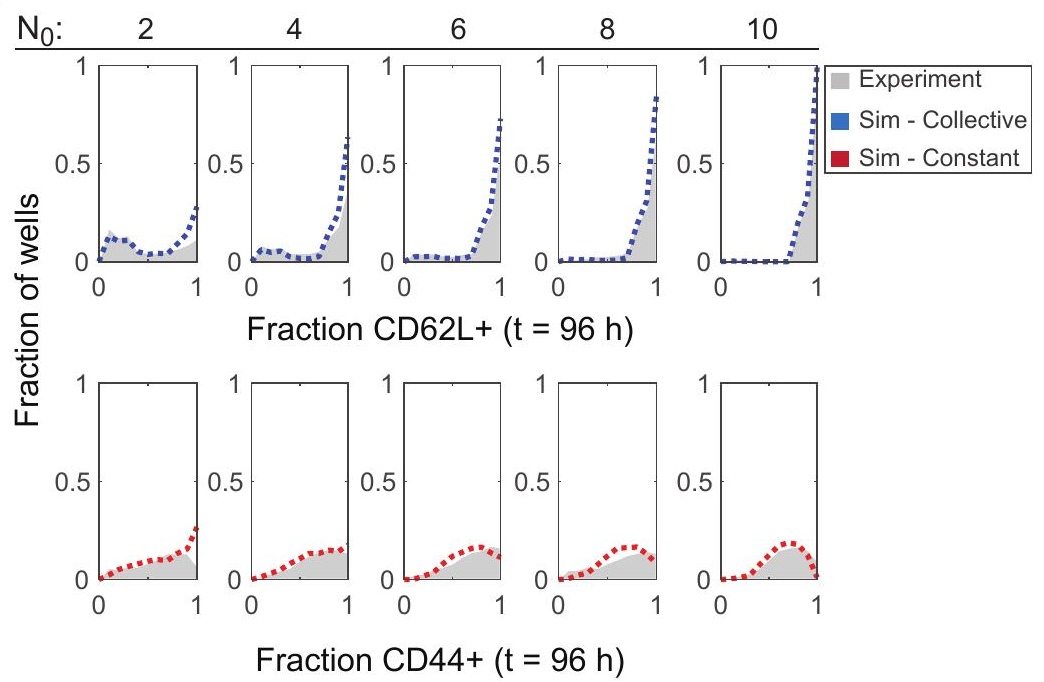

C

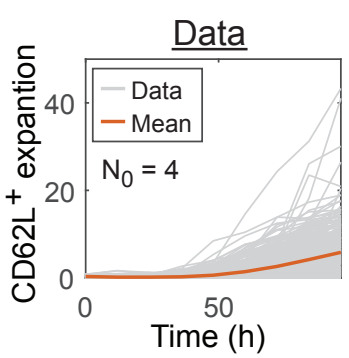

D

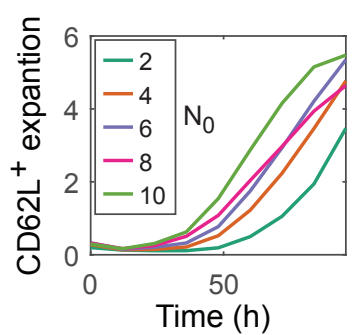

E

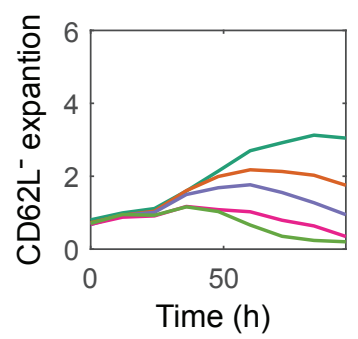

Simulation
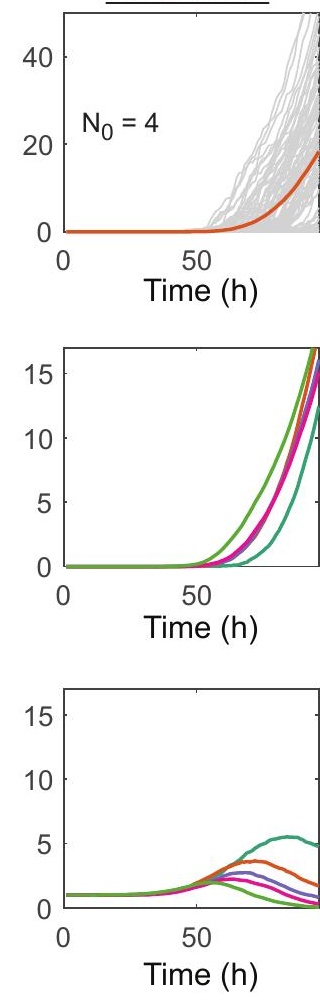


\section{Science \\ DIAAAS}

\section{Supplementary Materials for}

Induction of CD4 T cell memory by local cellular collectivity Michal Polonsky, Jacob Rimer, Amos Kern-Perets, Irina Zaretsky, Stav Miller, Chamutal Bornstein, Eyal David, Naama Kopelman, Gil Stelzer, Ziv Porat, Benjamin Chain*, Nir Friedman*

Correspondence to: $\underline{\text { b.chain@ucl.ac.uk, nir.friedman@weizmann.ac.i1 }}$

\section{This PDF file includes:}

Supplementary text

Figures $\mathrm{S} 1$ to $\mathrm{S} 16$

Tables $\mathrm{S} 1$ to S5

Movie S1. Cells proliferating and differentiating in a microwell during $96 \mathrm{~h}$.

Supplementary references $(48-50)$

Other Supplementary Materials for this manuscript includes the following:

Movie S1 


\section{Supplementary Text}

Analysis of Flow cytometry Data:

All analysis of flow cytometry data was performed using FlowJo software.

Statistical analysis:

All statistical testing was performed using MATALB with default parameters for each test. Student's $t$-test results are indicated in the relevant figures and figure legends. 1-way ANOVA was performed to test the relationship between different variables and initial cell numbers as indicated in the relevant sections in the text. The significance values and comparisons are summarized in Table S1.

2-way ANOVA was performed to compare CDC curves of all experimental conditions. For this test, we performed a 2-way ANOVA comparing each sample to its own control: All data points of the same sample, from all individual experiments harboring that sample were compared to the equivalent control ("No Ab" samples). The sample and cell number were used as the independent variables, and the corresponding CD62 $\mathrm{L}^{M A X}$ value as the response variable. Results are summarized in Table S2. This test was only performed on samples that were tests in at least two individual experiments.

To compare the expansion of cells over time for both experimental and simulated data, we used a repeated measure model with time as the within-subject factor and initial cell number as the measured between-subject effect. Results are summarized in Table S3.

\section{Analysis of live cell imaging data:}

Image analysis was performed using a custom-built MATLAB code. Analysis was performed in several steps: 1) Identification of microwells using edge detection in the bright-field images. 2) Background subtraction and illumination correction of fluorescent images. 3) Identification of total area of the cells using either edge detection in the brightfield images or gating on fluorescence images whenever CD45.2-APC was used. Only an area $\geq 50$ pixels was considered a true signal and processed further. Total cell area was calculated as the total area of cells / area of microwell. 4) An empirically set threshold was applied to fluorescent images to find the fraction of differentiated cells. For CD62L images, the threshold was set to capture the maximal number of positive cells in the initial images 
$(\mathrm{t}=0)$. Naïve cells are $\mathrm{CD}_{2} \mathrm{~L}^{+}$but with lower CD62L expression than that of pTCM (Fig. S1A-B) therefore this is a strict threshold. CD44 expressed only after $\sim 48 \mathrm{~h}$ and is then expressed at high levels (Fig. S1B). CD44 threshold was empirically set to capture a minimum number of positive cells at the initial time points, and a maximum of positive cells at later time points. For both cases (CD44 and CD62L), threshold values did not vary by more than $30 \%$ between experiments. Once the threshold was set, the fraction of positive cells was calculated as the area of positive cells / total area of cells (obtained at step 3), without any size filtering. 5) Initial cell and bead numbers in each micro-well were obtained using automatic fluorescence segmentation followed by manual correction to ensure accuracy.

\section{Critical area (Ac) and critical time (Tc) calculations:}

Ac was defined as the total cell area (calculated from time lapse images as described above) in which $50 \%$ of the cells in a well are differentiated. Tc was defined as the time in which $50 \%$ of the cells are differentiated. To calculate both parameters, traces of total area and of the fraction positive cells were smoothed. Time lapse images were taken every $2-6 \mathrm{~h}$. Thus, linear interpolation was performed on the smoothed traces to gain a refined trace with 96 time points (every hour). Since CD62L expression is high on naïve cells, CD62Lpositive traces typically decrease and then increase again as CD62L is re-expressed (Fig. 2B and S1A-B). Thus, Tc was identified only after the trace begun to increase (as shown in Fig. 2H) and early CD62L expression was not considered. Ac was calculated as the total cell area (in the smoothed trace) at Tc.

\section{Collective Differentiation Curve (CDC) calculation:}

To calculate CDC curves, data points of all microwells in all time points were projected on the CD62L - area plane and binned on each dimension (10 bins for the area, and 20 for CD62L). First, the number of data points in each bin was calculated. Most data points concentrate at high or low area / CD62L. Thus, to observe the behavior of the data at middle Area values, well numbers were normalized over each area bin, such that the total frequency of data points in each bin $=1$ (Fig. 2J-left). To calculate CD62L ${ }^{M A X}$, the CD62L bin which holds the maximum frequency of data points is identified for each area. In a case where more than one CD62L bin holds the same frequency of data points, the median value 
of those bins is calculated. Area values were converted into cell numbers using the empirically derived equation: $N=61.9$ x area -5.1 presented in Fig. S5B. The obtained CD62 $\mathrm{L}^{M A X}$ values are then plotted against the calculated cell numbers $(N)$ and fitted with a logistic function of the form:

$$
F(N)=\frac{M}{\left(1+e^{-r\left(N-N_{C}\right)}\right)}
$$

Where $M$ is the maximum fraction of $\mathrm{CD} 2 \mathrm{~L}^{+}$cells, $N c$ is the number of cells in which half have differentiated and $r$ defines the steepness of the curve. CDC calculated for the control conditions ('No Ab', Fig. 2J-right, 5A and S13B) was averaged over eight individual experiments. Logistic fit parameters for the control sample are: $M=0.95, N c=30$, and $r=$ 0.25 , and were used for the stochastic simulation described below.

\section{$\underline{\text { Stochastic simulations of cell differentiation }}$}

A stochastic computational model for cell differentiation was constructed using MATLAB. The model simulates a transition from a non-differentiated to differentiated cell, in simulated microwells starting with 1 to 10 initial cells $\left(\mathrm{N}_{0}\right)$. The simulation was repeated 100 times for each $\mathrm{N}_{0}$, and results are summarized over all iterations. Cells proliferated, died and differentiated stochastically. Two models describing differentiation were tested: 1 ) constant differentiation rate $R_{\text {constant }}$; and 2) collective differentiation rate where $R_{\text {collective }}$ depends on the number of interacting cells in a microwell $(N)$. As we experimentally observed dependence of differentiation on $N$, we assumed $R_{\text {collective }}$ had the same functional form as the CDC curve. Thus we use a logistic function to describe it:

$$
R(N)=\frac{M}{\left(1+e^{-r\left(N-N_{C}\right)}\right)}
$$

Parameters of $R$ were optimized by scanning a range of values for Max, $r, N c$ and $R_{\text {constant }}$, and calculating the model error in each iteration (Fig. S9). This was done by comparing model outcome to experimental data distributions (either $\mathrm{CD} 62 \mathrm{~L}^{+}$or $\mathrm{CD} 44^{+}$) over all initial cell numbers $\left(\mathrm{N}_{0}\right)$ values at $96 \mathrm{~h}$ (as in Fig. 3B). Least mean square error was calculated for each $\mathrm{N}_{0}$ (simulation vs. data) and summed over all $\mathrm{N}_{0}$ in each iteration. Experimental data was combined from three experiments as in Fig. $3(n=1,734)$. Parameters describing $R_{\text {collective }}$ were stable over a wide range of values with minimal error (Fig. S9A-B). Thus, 
we chose to use the parameters obtained directly from the logistic curve fitted to the experimentally obtained CDC described above ("No Ab" sample Fig 2J). Thus, for our collective model, all parameters used to simulate differentiation were derived directly from experimental data. $R_{\text {constant }}$ was less stable and gave a minimum error between 0.1 and 0.2 . A value of 0.15 was used for the simulation runs (Fig. 9C). Comparing a simulation using $R_{\text {constant }}$ to CD62L data gave a minimal error of $\sim 2.5$, which was much higher than the error of $R_{\text {collective }}$ using optimal parameters.

Division times ( $P^{\prime}$, first division; $P$, subsequent divisions) of each cell in the simulated microwell were drawn randomly from a right-skewed distribution derived from experimental data of single cells growing in microwells. Two different distributions were used, one describing the first division with longer division times, and the second describing subsequent divisions with faster division times (Fig. S8). We further assumed cells had an unlimited number of divisions. The model assumed identical division times between differentiated and non-differentiated cells. Experimentally, we observed that CD62Lexpressing cells had a slightly slower proliferation rate (Fig. 1D and S2). Thus we wanted to verify that our model assumption was valid and did not change the model outcome significantly. We tested this by running the simulation while multiplying the randomly sampled division times of differentiated cells by a factor of two or three. This was done only on subsequent divisions and not on the first division. Delaying the division time did not have a pronounced effect on the simulation outcome when $R_{\text {collective }}$ was used (simulating differentiation into CD62 $\mathrm{L}^{+}$cells). Simulation output when divisions were delayed and when $R_{\text {constant }}$ was used, did not describe $\mathrm{CD}_{4} 4^{+}$data as well as when no delay is introduced. These results are presented in Fig. S10. Thus, we contend that assuming identical division rates for differentiated and non-differentiated cells is valid in this case. Experimentally observed differences in the proliferation of CD62L-expressing cells does not influence the fraction of differentiated cells at the early time points observed and simulated here.

The death rate (D) was estimated from experimental data(30) to be $\sim 0.15 \mathrm{~h}^{-1}$. We then estimated the death rate per cell cycle to be $0.15 \mathrm{x}(37 / 11) \sim 0.5$ up to the first division 
(average time of first division $\sim 37 \mathrm{~h}$ ), and $0.15 \times(11 / 11)=0.15$ for subsequent divisions (average time of subsequent division $\sim 11 \mathrm{~h}$ ).

The simulation was performed by iterating over $96 \mathrm{~h}$ for each run $(10$ cell numbers, 100 iterations each), each time calculating the number of live cells and remaining time for the next division. Once the division time reached 0 (the cell divided at the current step of the model), the cell could differentiate and proliferate, proliferate without differentiating or die, according to the rates described above. For a stochastic selection of one of these fates, a random value is drawn (from a uniform distribution between 0 and 1) and compared to the death or differentiation rates. Whenever the random value is lower or equal to that rate, the cell will acquire the associated fate. Once a cell is differentiated, all of its progeny is differentiated as well. At each time point, the number and fraction of differentiated cells is calculated. Numbers are extracted for all microwells and compared to experimentally obtained data on $\mathrm{CD}_{62} \mathrm{~L}^{+}$and $\mathrm{CD} 44^{+}$data. Ac and Tc values were also obtained from the simulation output and compared to experimental data (Fig. S11A-D).

\section{$\underline{\text { RNA sequencing analysis }}$}

RNA-seq reads were aligned to the mouse reference genome (NCBI 37, mm9) using TopHat v2.0.13 with default parameters (48). Duplicate reads were filtered if they aligned to the same base and had identical UMIs. Expression levels were calculated for each sample to the total number of reads using HOMER software (http://homer.salk.edu)(49). Further sample normalization and analysis was performed using DEseq2(50). For Gene Ontology (GO) analysis (Fig. 1E), genes with a log fold change $\geq 0.5$ were chosen (total of 1194 genes) and analyzed using the MouseMine data base. GO enrichment was evaluated by comparing differentially expressed genes to all genes in our data which were expressed above noise ( 9,000 genes). Reported P-values were calculated using the BenjaminiHochberg correction. PCA (Fig. S7) was constructed using differentially expressed genes ( $\mathrm{P} \leq 0.05$, Benjamini-Hochberg correction), with $\log 2$ fold change of $\geq 1$ between $48-h$ and $72-\mathrm{h}$ time points. 
A

$\underline{\mathrm{Oh}}$

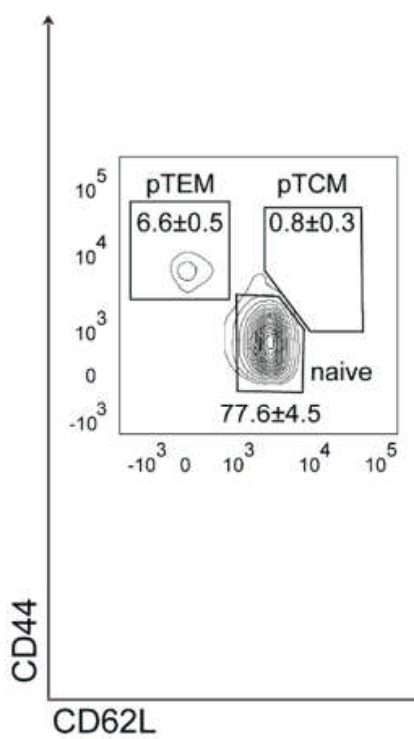

B
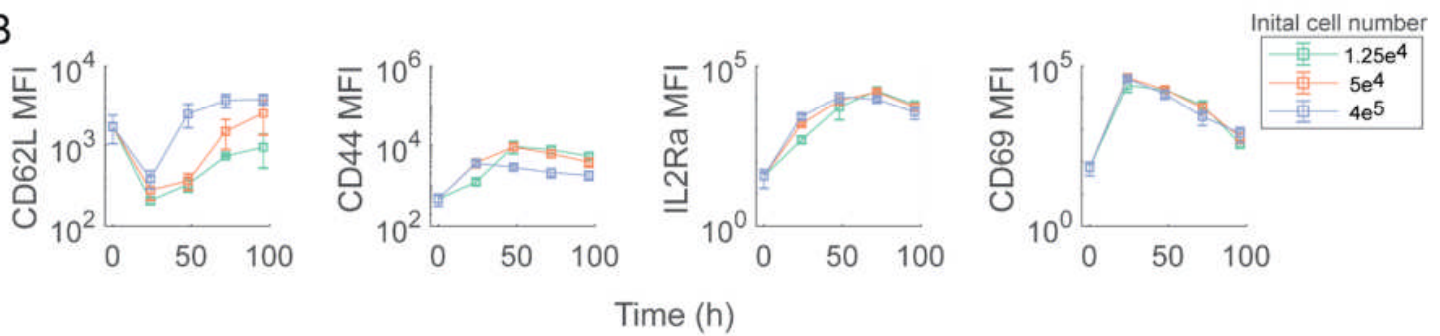

C
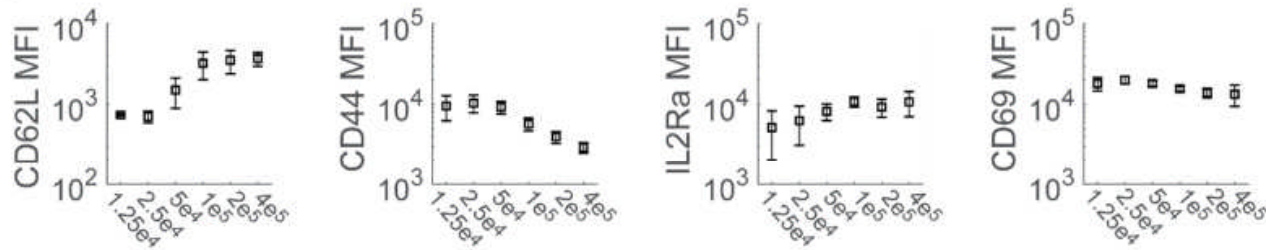

Initial cells

$\underline{72 h}$
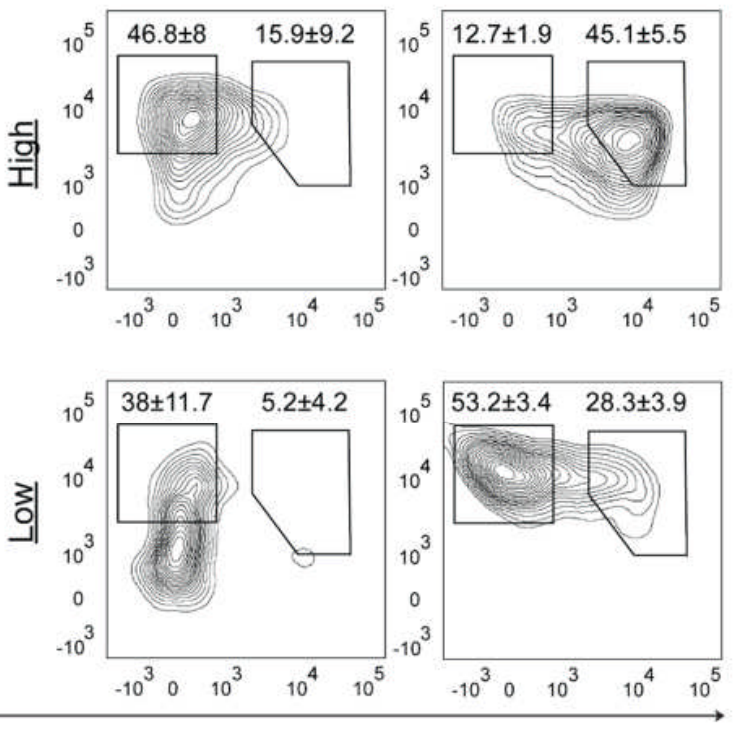

Time (h)

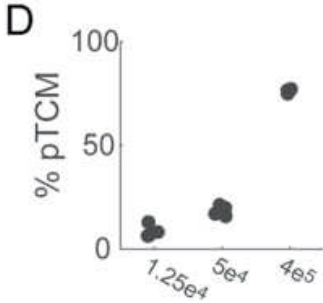

Figure S1. CD62L varies over initial cell concentrations while other activation markers do not. A) Phenotypic analysis of $\mathrm{CD} 4^{+} \mathrm{T}$ cells cultured ex vivo for $72 \mathrm{~h}$ at high ( $4 * 10^{5}$, top) and low $\left(0.125 * 10^{5}\right.$, bottom) initial cell numbers. Cells were cultured for $96 \mathrm{~h}$ and activated using anti-CD3 / anti-CD28 microbeads. Percentage of naïve 
$\left(\mathrm{CD} 2 \mathrm{~L}^{+} \mathrm{CD} 44^{-}\right)$, pTEM $\left(\mathrm{CD} 62 \mathrm{~L}^{-} \mathrm{CD} 44^{+}\right)$and pTCM $\left(\mathrm{CD} 62 \mathrm{~L}^{+} \mathrm{CD} 44^{+}\right)$populations are indicated in one representative experiment out of three, with a total of $n=7$ wells in all experiments. Mean \pm SEM for all experiments are shown. B) CD62L, CD44, IL2Ra (CD25) and CD69 MFI plotted over time for three initial cell numbers $\left(4 * 10^{5}, 5 * 10^{4}\right.$, $1.25 * 10^{4}$ initial cells). C) Same data as in B, MFI for each marker is plotted at $48 \mathrm{~h}$ against six initial cell numbers. ANOVA test shows that the MFI of CD62L and CD44 changes with cell number $\left(\mathrm{P}<10^{-4}\right.$, Table S1), whereas the MFI of CD25 and CD69 does not. All cells in A-C were cultured in 96-well plates in a $200 \mu \mathrm{l}$ culture medium. Data in B-C is averaged over three individual experiments. Error bar reports SEM. D) Percent pTCM plotted for three initial cell numbers $72 \mathrm{~h}$ after activation with PMA+ionomycin. Data is of one representative experiment out of three. 
A
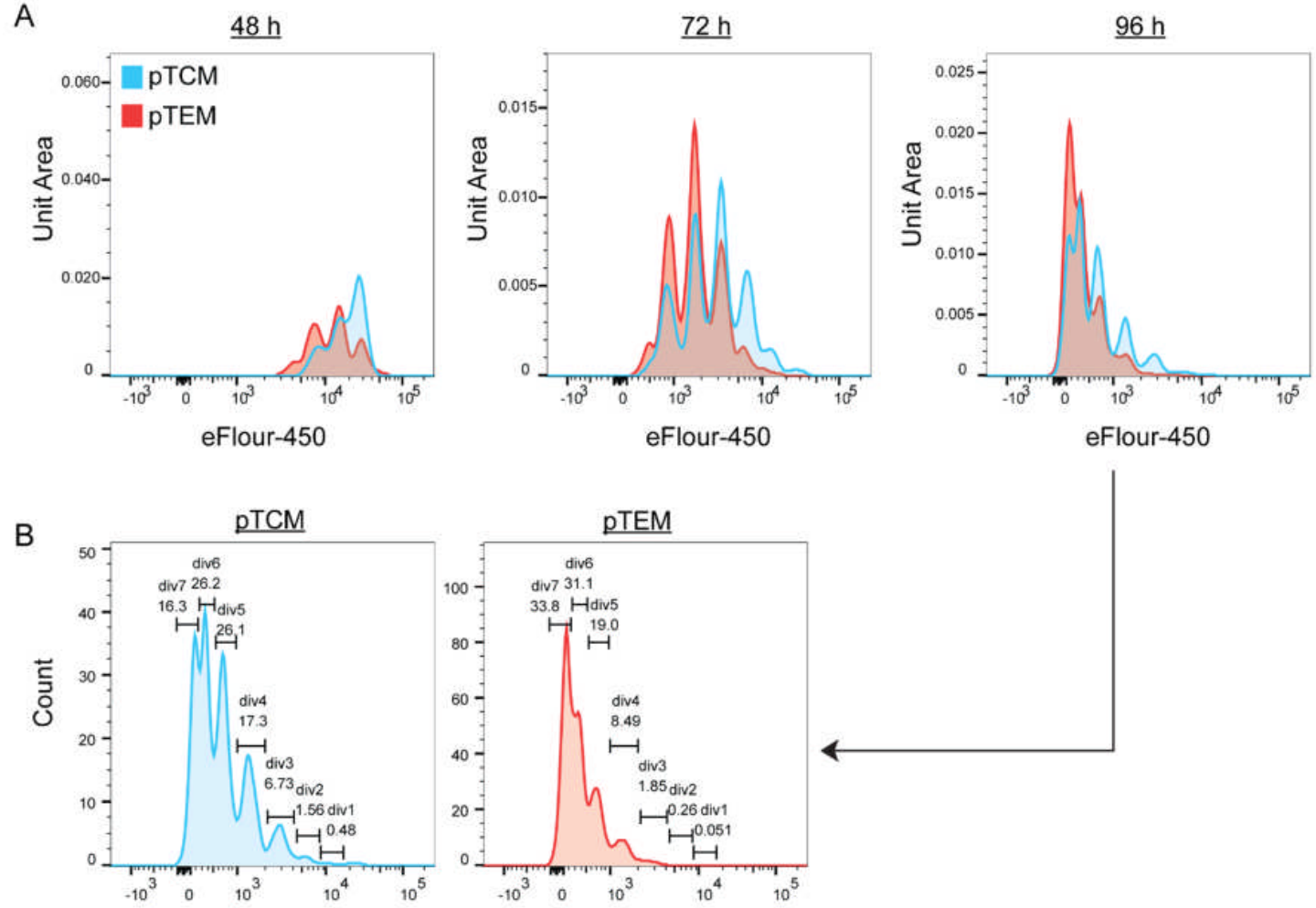

eFlour-450

Figure S2. Proliferation of pTCM is lower compared to pTEM. Naive CD4 T cells were labeled with eFluore-450 cell proliferation dye and cultured in a 96-well plate with an initial cell number of $1.25 * 10^{4}$ cells/well. Cells were activated using activation microbeads. After 48, 72 and $96 \mathrm{~h}$ of culture proliferation of pTCM and pTEM cells (gated as in Fig. S1) was analyzed using flow cytometry. Data is of one representative experiment out of the three shown in Fig. S1. A) Proliferation data of pTCM and pTEM at 48, 72, and 96 h. B) Same plot as in A - left, showing the fraction of cells at each division. 


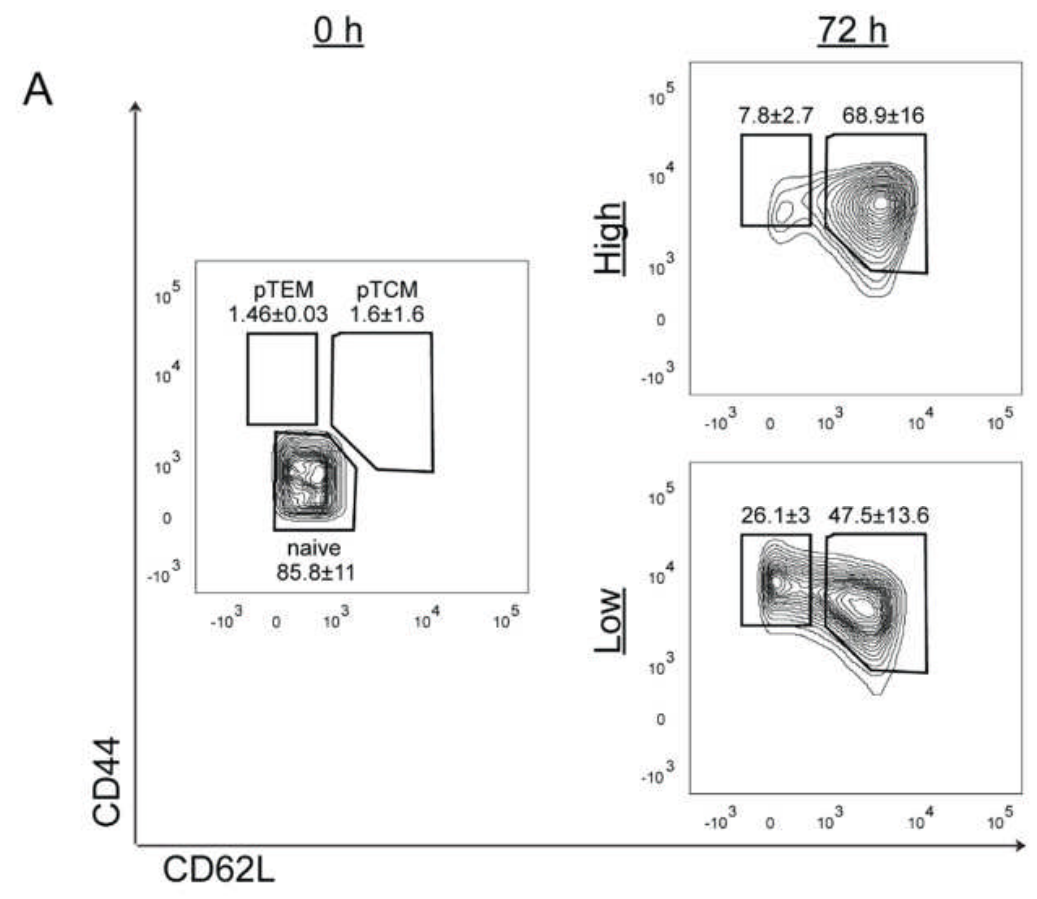

B
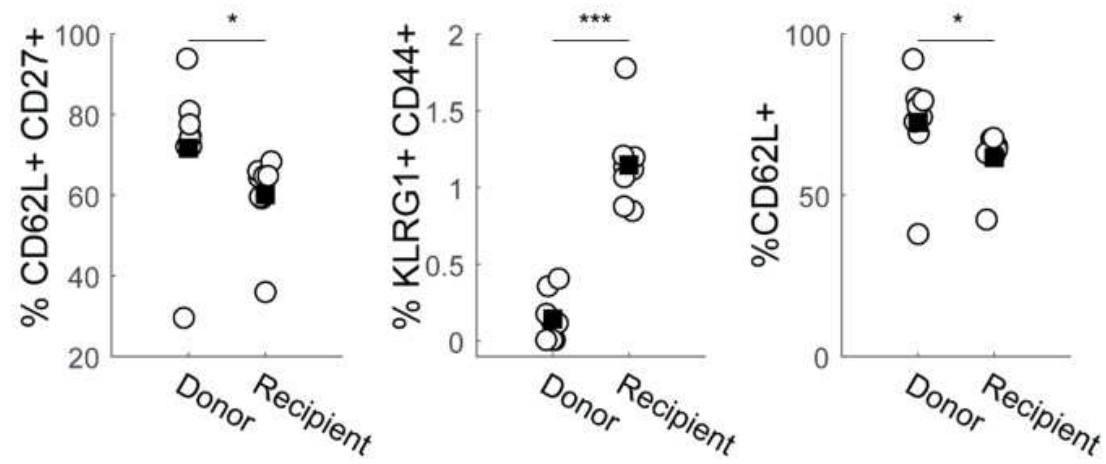

Figure S3. pTCM cells generated ex vivo are long lived in vivo and express central memory markers. Naïve $\mathrm{CD}^{+} \mathrm{T}$ cells from CD $45.1^{+}$mice were cultured ex vivo for 72 $\mathrm{h}$ in a 6-well plate in either high or low initial concentrations $\left(2 * 10^{6}\right.$ and $6.25 * 10^{4}$ cells $/ \mathrm{ml}$, respectively). Cells were activated using activation microbeads. After $72 \mathrm{~h}$ of culture dead cells were removed and either $2 * 10^{6}$ or $1 * 10^{6}$ cells (depending on the experiment) were injected into $\mathrm{CD} 45.2^{+}$recipients. A) Phenotypic analysis of naive CD45.1 $1^{+}$cells and of cells cultured at high and low initial concentrations for $72 \mathrm{~h}$. Naïve $\left(\mathrm{CD} 62 \mathrm{~L}^{+} \mathrm{CD} 44^{-}\right)$, pTEM $\left(\mathrm{CD} 62 \mathrm{~L}^{-} \mathrm{CD} 44^{+}\right)$and pTCM $\left(\mathrm{CD} 62 \mathrm{~L}^{+} \mathrm{CD} 44^{+}\right)$population are indicated. Mean \pm SD are shown for each group. B) Percent of central memory 
$\left(\mathrm{CD} 62 \mathrm{~L}^{+} \mathrm{CD} 27^{+}\right.$, left), activated effector $\left(\mathrm{KLRG}^{+} \mathrm{CD}_{4} 4^{+}\right.$, middle) and $\mathrm{CD} 2 \mathrm{~L}^{+}$(right) populations, comparing donor and recipient CD4 T cells > 35 days post-transfer. Only mice injected with CD45.1 $1^{+}$cells cultured in high initial densities were included in the analysis. Data is of a total of eight mice from two independent experiments ( $n=4$ mice/experiment). Indicated significance values were obtained using a paired Student's $t$-test $(*, \mathrm{P}<0.05$; **, $\mathrm{P}<0.01 ; * * *, \mathrm{P}<0.001)$.

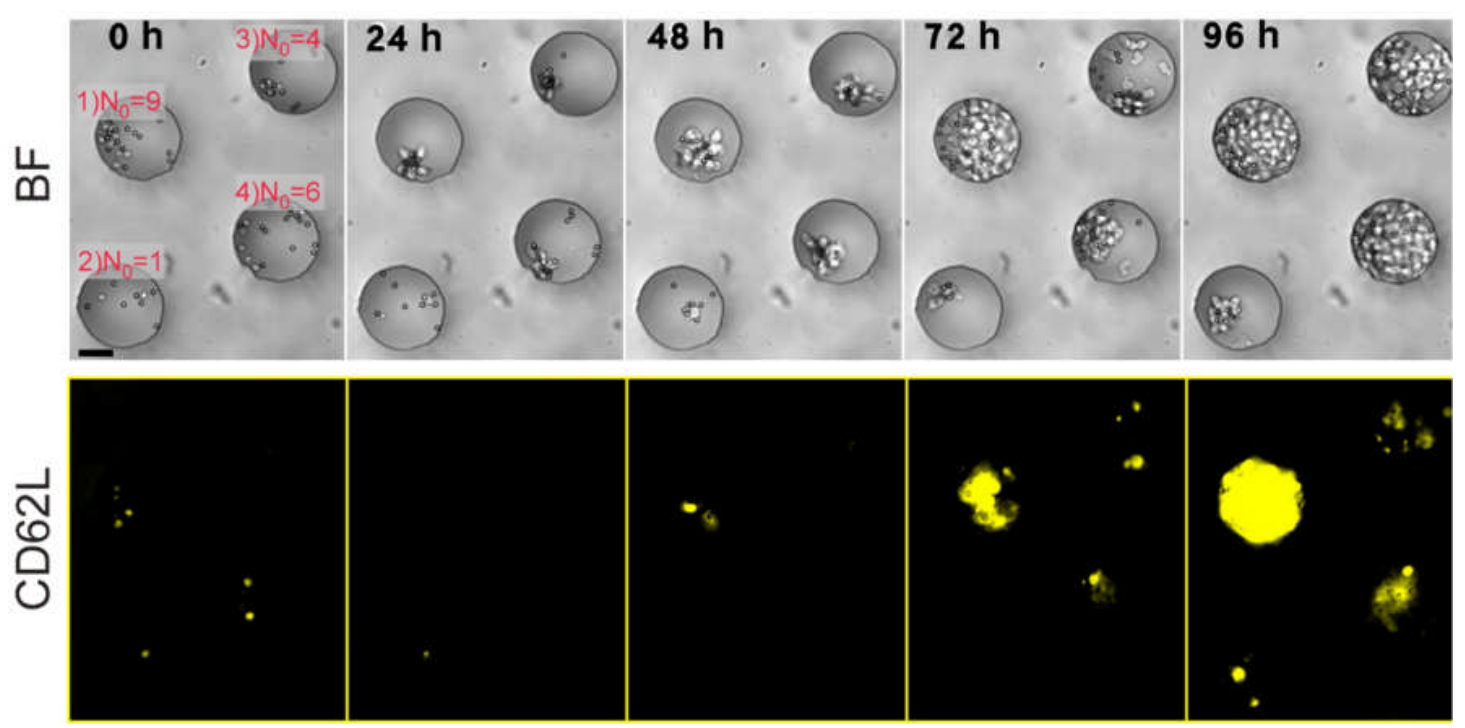

Figure S4. Cells in adjacent microwells have different fates, influenced by cell numbers within each microwell. Images of four adjacent microwells from one representative field of view. Top: bright-field illumination; bottom: CD62L florescence. Time is indicated at the top left corner, scale bar $=20 \mu \mathrm{m}$. Each microwell contained a different number of cells at $\mathrm{t}=0\left(N_{0}\right)$. Wells are numbered 1-4 and contain: 9, 1, 4, and 6 initial cells, respectively. After $96 \mathrm{~h}$ of culture, the calculated fraction of CD62L $\mathrm{L}^{+}$cells in each microwell was: $0.99,0.17,0.55$, and 0.79 for wells $1-4$, respectively. 

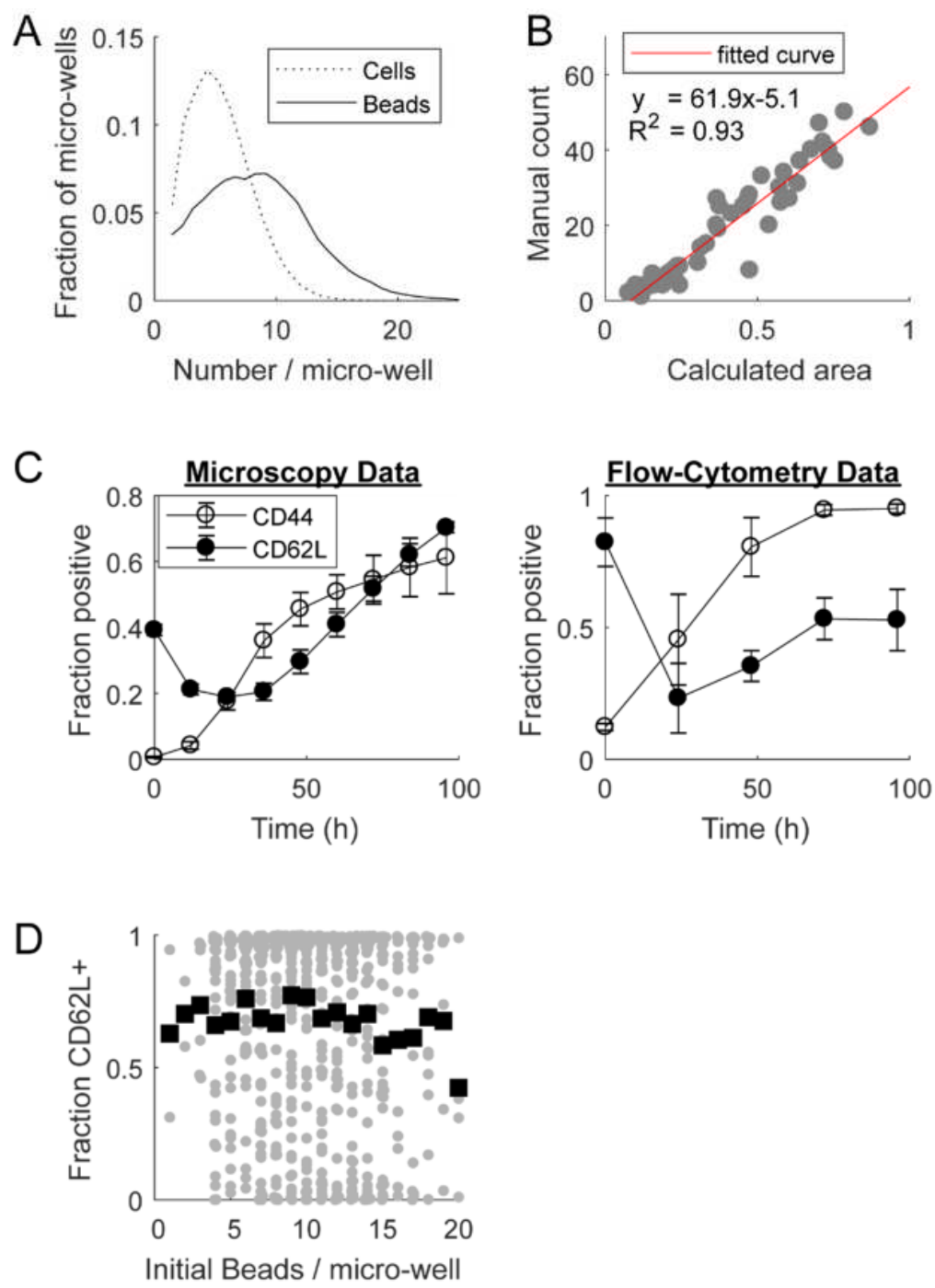

Figure S5. Calibration of cell and micro-bead seeding in microwells. Area calculation, marker expression and the effect of microbead numbers. A) Distribution of initial cell numbers (mean $=4.7 \pm 2.6)$ and micro-bead numbers $($ mean $=8.5 \pm 4.5)$. B) Manual cell count vs. automatically calculated area. 72 microwells from two individual experiments were measured at varying time points. Data was fitted to a straight line. A small offset in the calculated area is caused by the method used for segmentation of the cells (see supplementary text for a detailed explanation of segmentation). C) CD62L (filled circles) and CD44 (empty circles) expression over $96 \mathrm{~h}$ of culture, measured using dynamic antibody stain in time-lapse movies in microwells (left) or by flow cytometry of bulk 
cultures (right). Microscopy data is averaged over all microwells in two individual experiments with a total of $n=1324$ microwells in both. Flow cytometry data is averaged over three individual experiments, as in Fig S1. In both microscopy and flow cytometry samples the initial number of cells/96-well is $1.25 * 10^{4}$. Error bars show SEM. D) Fraction $\mathrm{CD}^{2} 2 \mathrm{~L}^{+}$cells at $\mathrm{t}=96 \mathrm{~h}$ plotted against the number of activation beads in each microwell. Each dot is an individual microwell and squares represent median values. Data is from one representative experiment, $\mathrm{n}=663$ microwells.

A

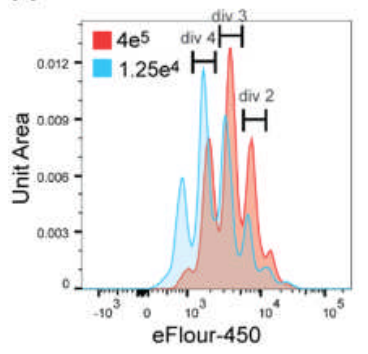

B

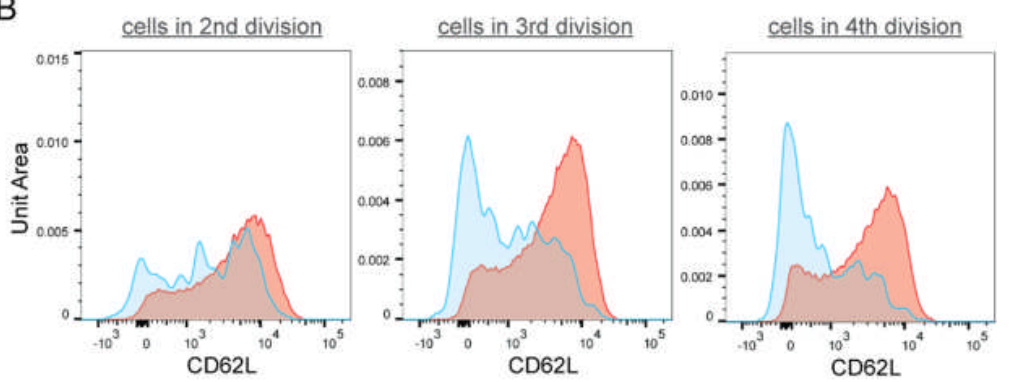

Figure S6. CD62L expression depends on cell density and not on the number of cell divisions. A) Proliferation profile of cells cultured in two initial densities ( $4 * 10^{5}$ and 1.25 * $10^{4}$ cells/96-well, red and blue curves respectively) measured using the cell proliferation dye eFlour-450. Cells were activated using activation microbeads. Proliferation was evaluated after $72 \mathrm{~h}$ of culture and is shown for one representative sample in one experiment out of three. B) CD62L expression of cells from the two samples in A, which have gone through 2, 3, and 4 division cycles (gated as indicated on the plot in A). 


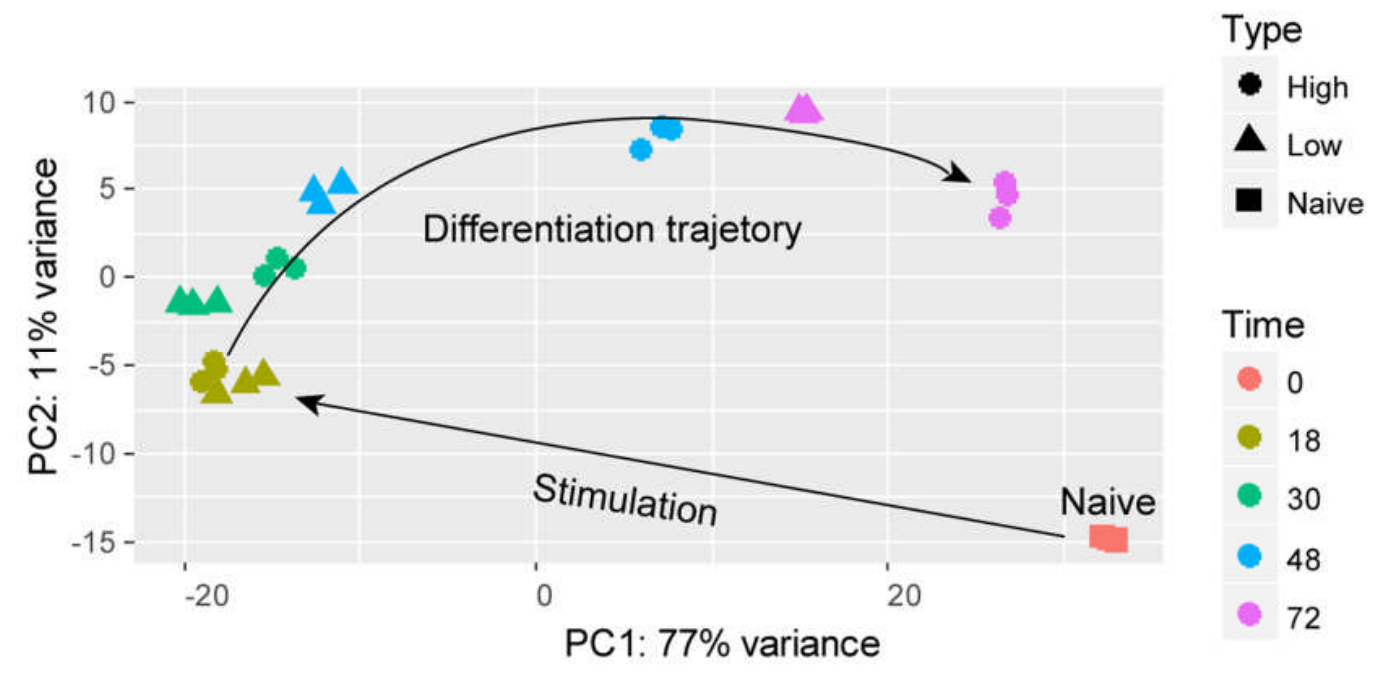

Figure S7. PCA of RNA-seq data from cells cultured in high and low initial densities. Naïve $\mathrm{CD}^{+} \mathrm{T}$ cells were cultured for $18,30,48$, and 72 hours at a starting concentration of either $10^{6}$ or $6.25 * 10^{4}$ cells $/ \mathrm{ml}$ in $24-w e l l$ plates, and activated using microbeads. At the indicated time points, live $\mathrm{CD} 4^{+} \mathrm{T}$ cells were lysed and subjected to genome-wide gene expression analysis using RNA-seq. Results were analyzed using DESeq2. Differentially expressed genes ( $\mathrm{P} \leq 0.05$, Benjamini-Hochberg correction), with a $\log 2$ fold change of $\geq$ 1 between 48 and $72 \mathrm{~h}$ time points were used to construct the PCA plot. Data is from one experiment with three technical repeats. 

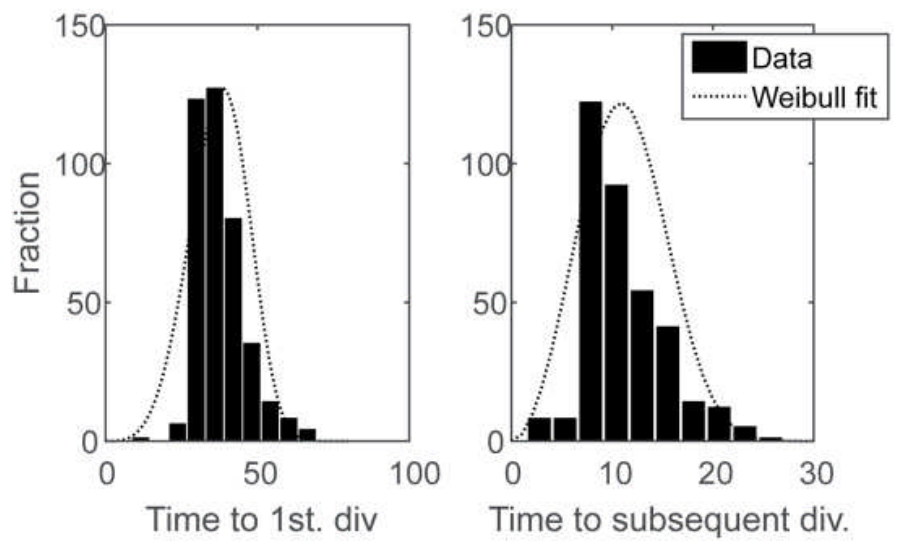

Figure S8. Weibull distribution fit to first and subsequent division times. Times for the first division (left) and subsequent divisions (right) were determined experimentally by direct measurement of division times of 389 single $\mathrm{T}$ cells cultured and activated in microwells at identical conditions to the samples presented in the main text. A Weibull distribution was fitted to the experimental data and used in the model to determine division times of the first $($ mean $=37.2 \pm 9.6 \mathrm{~h})$ and of subsequent $($ mean $=11.2 \pm 4.2 \mathrm{~h})$ divisions of each cell. 

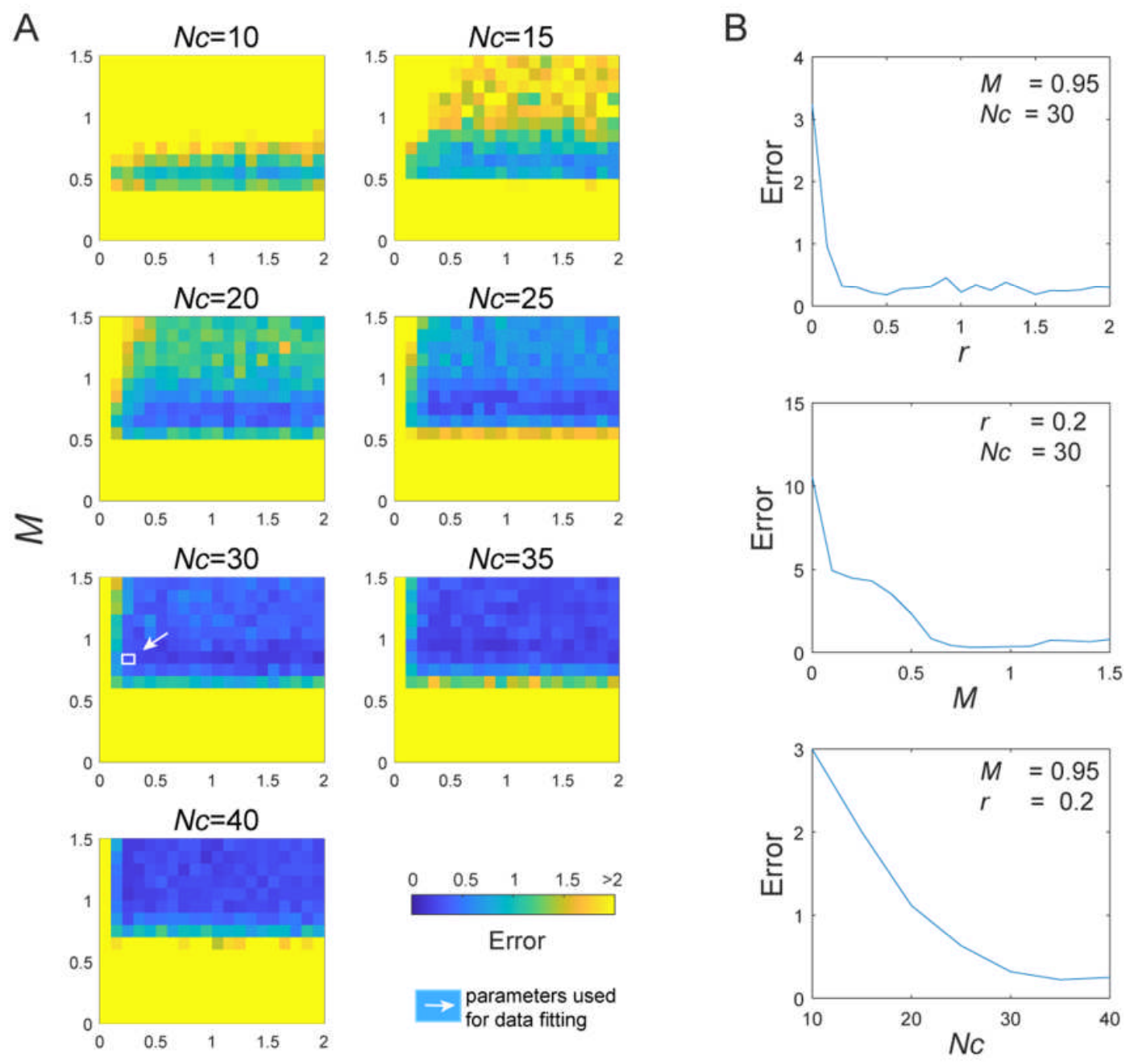

$r$

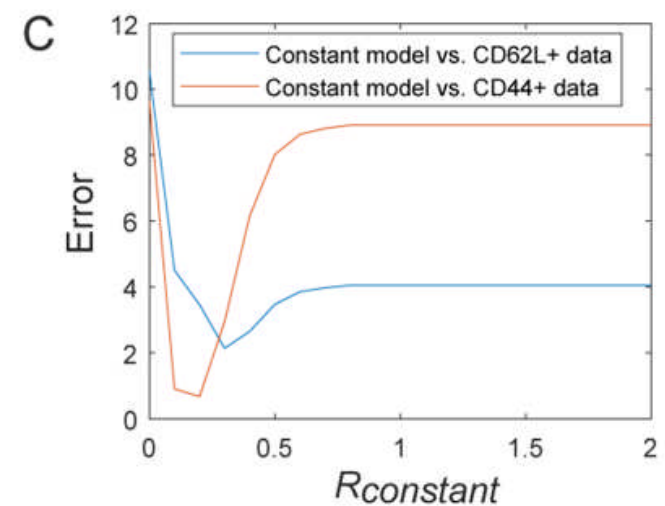

Figure S9. Scanning the parameters used to simulate collective and constant differentiation rates. The three parameters used to simulate collective differentiation $(M$, 
$r$ and $N c)$ as well as the constant differentiation rate $\left(R_{\text {constant }}\right)$ were scanned over a range of values, each time calculating the model error. Output was compared to experimental data distributions (either $\mathrm{CD}_{2} \mathrm{~L}^{+}$or $\mathrm{CD} 44^{+}$) as in Fig. 3. Least mean square error was calculated for each $N_{0}$ (simulation vs. data) and summed over all $N_{0}$ values (1 to 10) in each iteration. A) Logistic model error over a range of $M$ (rows), $r$ (columns) and $N c$ (individual plots). Error was calculated comparing the simulation outcome to CD62L data. White arrow indicates the parameter combination that was extracted from the experimental CDC and was used to run the simulation in Fig. 3, Fig. 5, Fig. S10 and S11. B) One dimensional parameters scan, each time fixing two parameters on the point marked in A (parameter combination used in the analysis) and changing the third one. C) $R_{\text {constant }}$ error calculated against $\mathrm{CD}_{2} \mathrm{~L}^{+}$(blue) and $\mathrm{CD} 44^{+}$(red) experimental data.
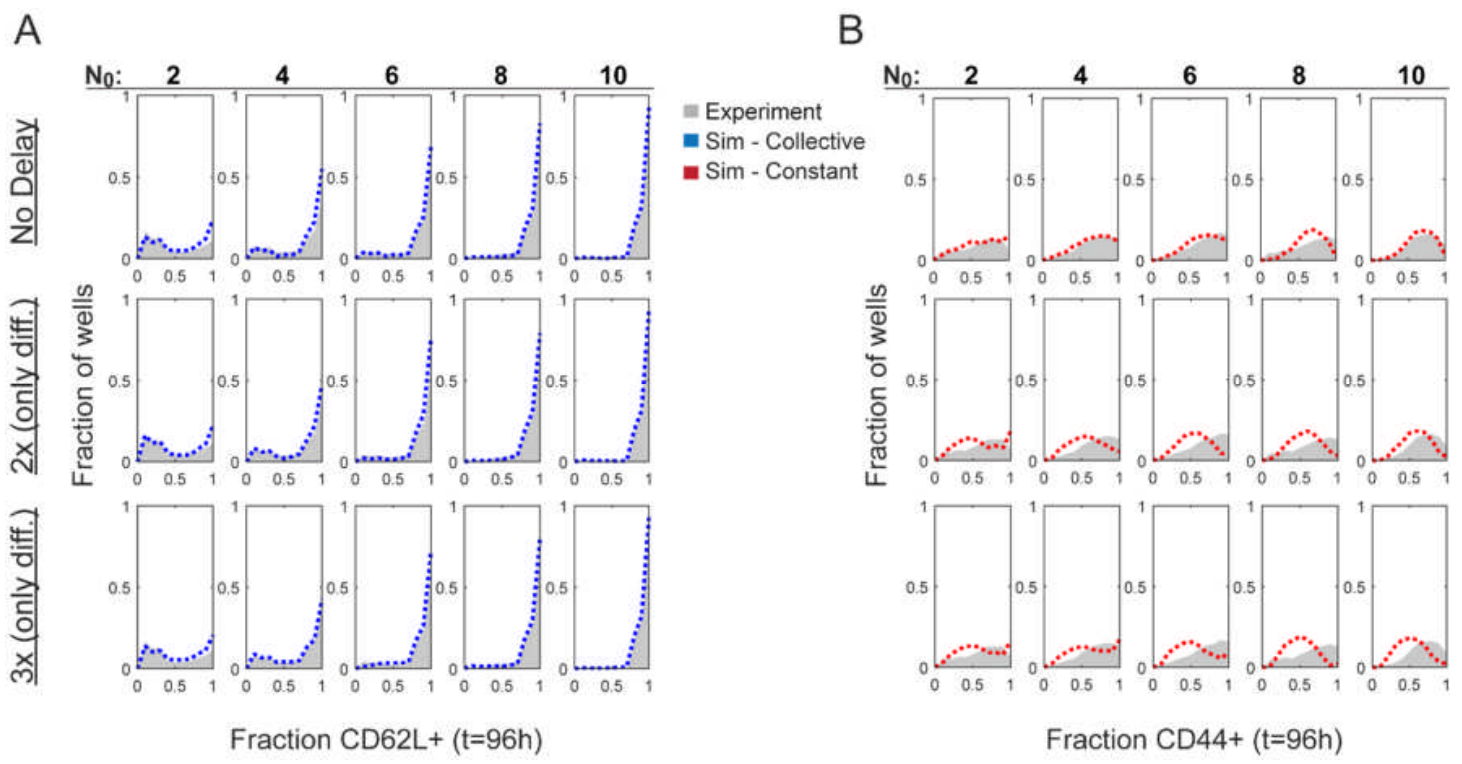

Figure S10. Simulation output when increasing the division time of differentiated cells. Distributions of experimentally obtained $\mathrm{CD}_{2} 2 \mathrm{~L}^{+}(\mathrm{A})$ and $\mathrm{CD} 44^{+}(\mathrm{B})$ fractions (gray curves) are compared to output of simulations assuming collective (blue) and constant (red) differentiation rates. Each row compares experimental data to output of the simulation where the division time of differentiated cells was increased. The increase in division time is introduced only at the subsequent divisions (not at the first division), such that the division time of each differentiated cell is multiplied by a factor of 2 ("2x"), 3 ("3x") or 
kept identical to the un-differentiated cells ("No Delay"). Data are combined from three individual experiments as in Fig 2F-G and Fig 3.

A

$\underline{\mathrm{CD} 44}$

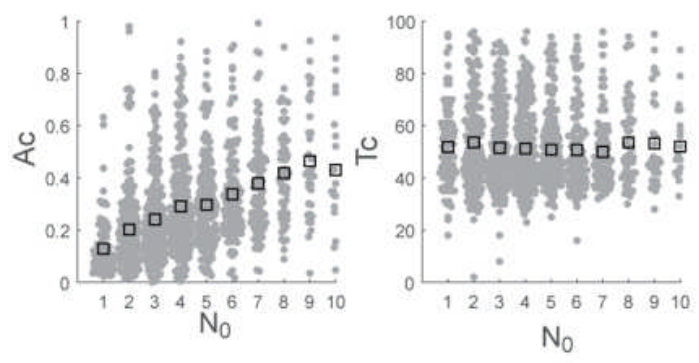

C

$\underline{\mathrm{CD} 62 \mathrm{~L}}$

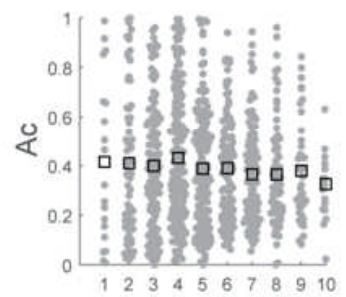

$\mathrm{N}_{0}$

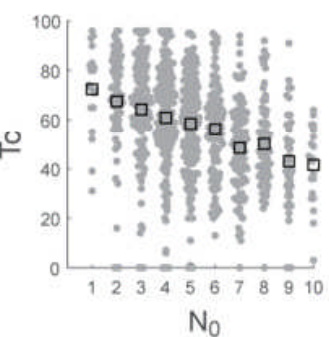

$\mathrm{N}_{0}$
B
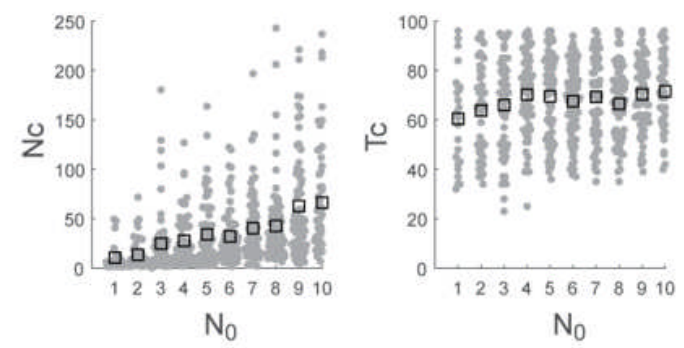

$\underline{\text { Sim - Logistic }}$
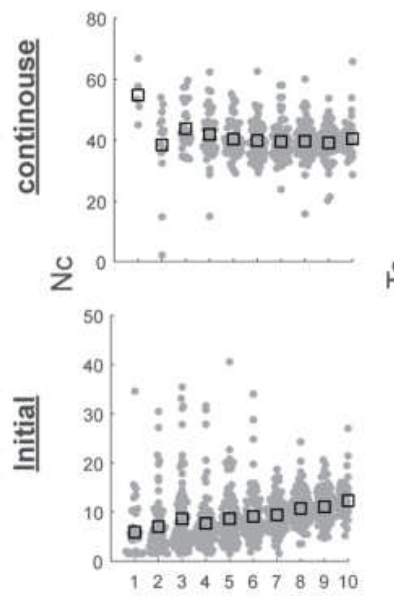

$\mathrm{N}_{0}$

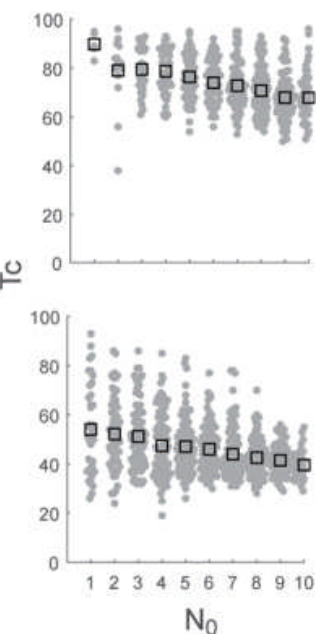

$\mathrm{N}_{0}$

$E$
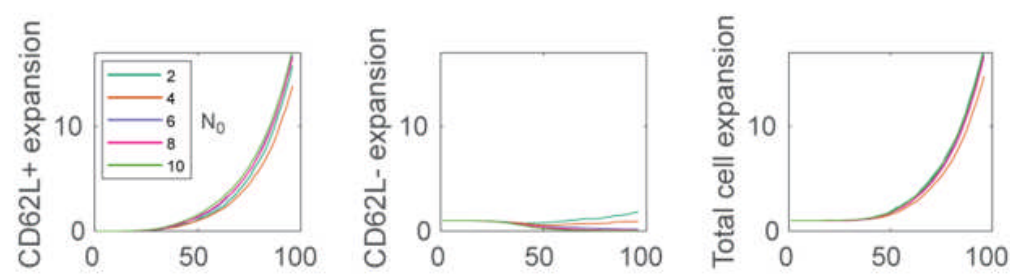

Time (h)

Figure S11. Tc and Ac values of CD44 and CD62L experimental data and for the collective and logistic simulations. Ac and Tc were calculated as described in the text and 
methods. A) Ac (left) and Tc (right) values calculated for CD44 expression and plotted over $N_{0}$ from three experiments as in Fig. 2F-G. Each dot is a microwell, squares represent mean values. B) Same as in A, plotted for output of a simulation assuming a constant differentiation rate. C) Same as in A, plotted for CD62L expression from the same experiment. D) Same as in C, plotted for output of a simulation assuming collective differentiation rate. Top: assuming $R_{\text {collective }}$ is continuously changing over time following change in cell number. Bottom: $R_{\text {collective }}$ is set once according to $N_{0}$, prior to the first cell division. E) Relative expansion in $\mathrm{CD}_{2} \mathrm{~L}^{+}$and $\mathrm{CD} 62 \mathrm{~L}^{-}$and total cell numbers, plotted for the result of a simulation assuming $R_{\text {collective }}$ is set only at the initial time point, thus depend only on $N_{0}$, and is not affected by changes in cell numbers.
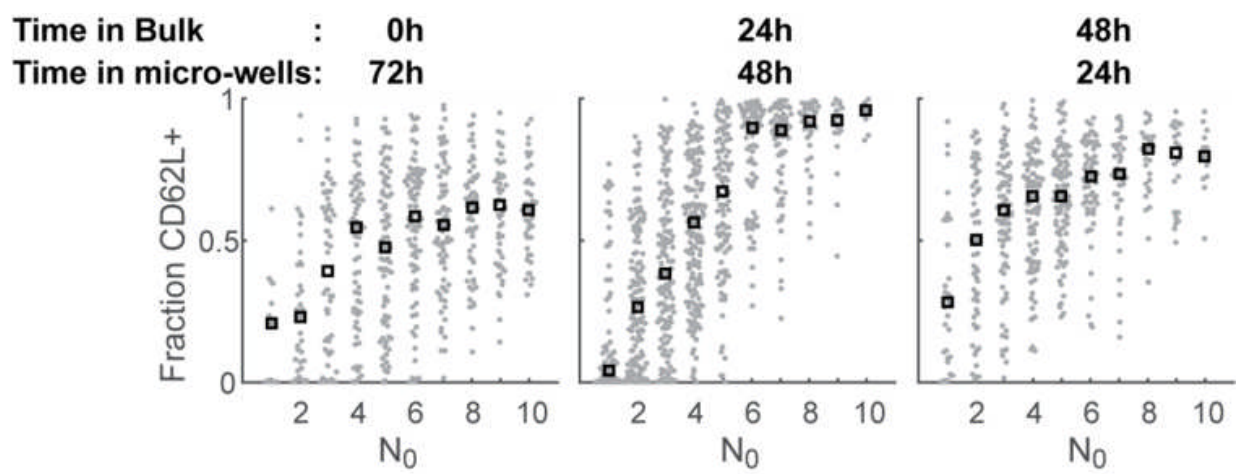

Figure S12. Differentiation rate is modulated by cell numbers for at least $48 \mathrm{~h}$ after activation. Naïve $\mathrm{CD}^{+}{ }^{+} \mathrm{T}$ cells were pre-cultured in bulk for 24 or $48 \mathrm{~h}$ in an initial concentration of $1 * 10^{6}$ cells $/ \mathrm{ml}$. Cells were activated using microbeads. At the indicated time points, cells were stripped from the beads using EDTA and dead cells were removed on a ficoll gradient. Live cells together with their conditioned growth medium were seeded into microwells with fresh activation microbeads as described above in the materials and methods section. Initial cell numbers/microwell were determined as before and cells were cultured for an additional time as shown. The CD62 $\mathrm{L}^{+}$fraction was evaluated after $72 \mathrm{~h}$ total (pre-culture and microwell culture) and plotted as a function of $N_{0}$ at the time of transfer. 
A
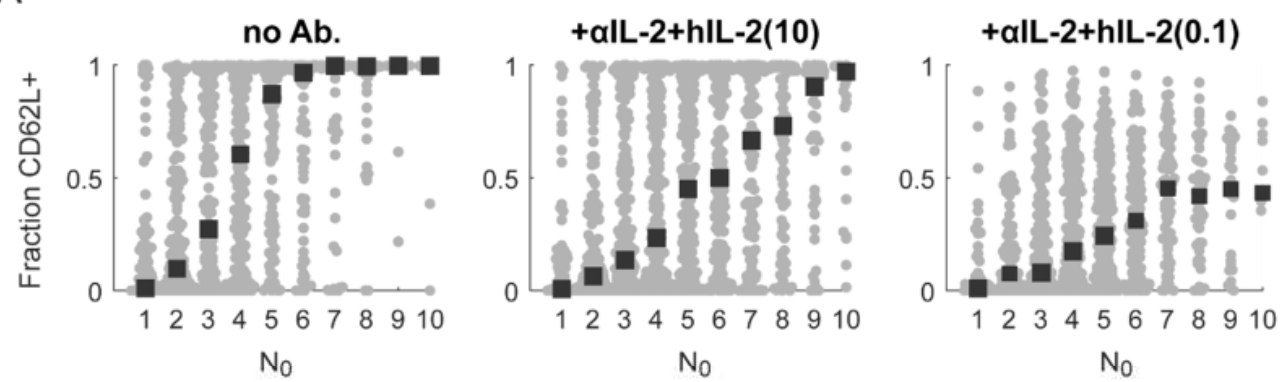

B

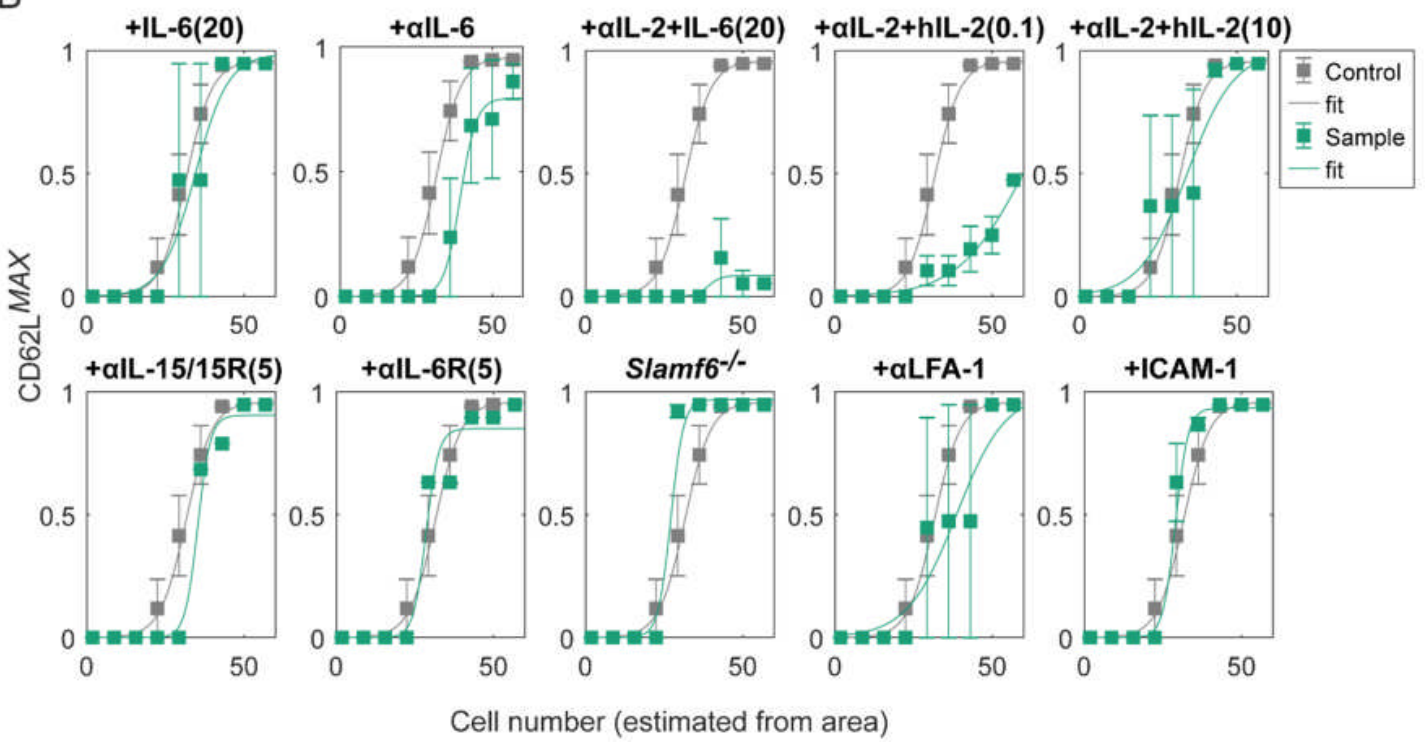

Figure S13. Perturbing CD62L expression in microwells. Several cytokines and adhesion molecules were tested for their influence on CD62L expression. Data presented are from a total of eight experiments, each with a different set of tested conditions. In all experiments Naïve $\mathrm{CD} 4^{+} \mathrm{T}$ cells were cultured in microwells as stated in the text and methods section, and subjected to different perturbations influencing either adhesion molecules or cytokine secretion. Conditions which showed some effect were tested further. Conditions which did not show any effect were not subjected to additional testing and were analyzed in one experiment only. The effect of the adhesion molecules ICAM-1, LFA-1, and Ly108 (SLAMF6) was tested by either coating the microwell surface with ICAM-1 protein ("+ICAM-1", $20 \mu \mathrm{g} / \mathrm{ml}$ ) or with anti-LFA-1 antibody ("+ $\alpha$ LFA-1", $20 \mu \mathrm{g} / \mathrm{ml}$ ), or by culturing naïve cells from Slamf6 ${ }^{-/}$mice. The effect of cytokines and cytokine receptors was tested using addition of blocking antibodies or cytokines to the culture medium at the culture start time. The following antibodies were added: anti-IL-2 ("+ $\alpha$ IL-2", $10 \mu \mathrm{g} / \mathrm{ml})$, 


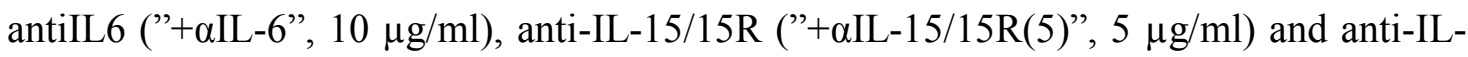

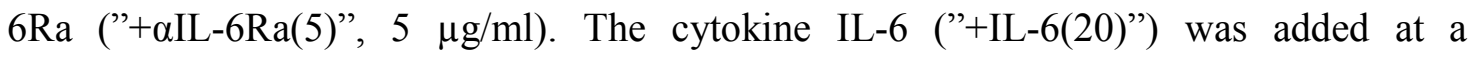
concentration of $20 \mathrm{ng} / \mathrm{ml}$. Human IL-2 ("+hIL-2") was added a concentration of 0.1 , and $10 \mathrm{ng} / \mathrm{ml}$ (indicated in brackets in the relevant plots). A) Fraction CD62 $\mathrm{L}^{+}$at $\mathrm{t}=96 \mathrm{~h}$, plotted over $N_{O}$ in three samples. Left: control, middle: blocking IL-2 while adding 10 ng/ml human IL-2, and right: blocking IL-2 while adding $0.1 \mathrm{ng} / \mathrm{ml}$ human IL-2. B) CDC curves for all the different perturbations. Control CDC (gray) were averaged over eight individual experiments and is identical in all CDC plots (same as in Fig. 2J). Error-bars show SEM. CDC curves for each of the experimental conditions (green) were compared to the control. CDC curves for the different samples were averaged over a varying number of experiments: CDC curves for anti-IL-15/15R and anti-IL-6Ra were derived from one experiment each. CDC curves for anti-IL-2 + IL-6, antiIL-2 + human IL-2 (10), IL-6, antiLFA-1, ICAM-1 and Slamf6 ${ }^{-/-}$were averaged over two experiments each. CDC curve for anti-IL-2 + human IL-2 (0.1) was averaged over three experiments. CDC for anti-IL-6 was averaged over four experiments. CDC plots of anti-IL-6, anti-IL-2 + IL-6 and Slamf6-were significantly different then the control as measured by 2-way ANOVA. Results are summarized in Table S2. 


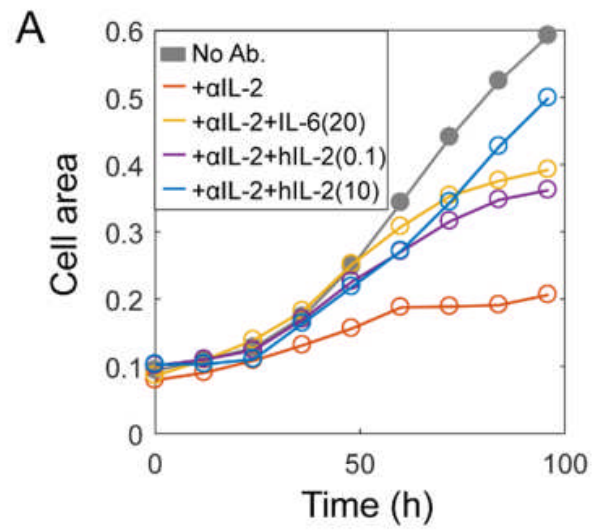

B
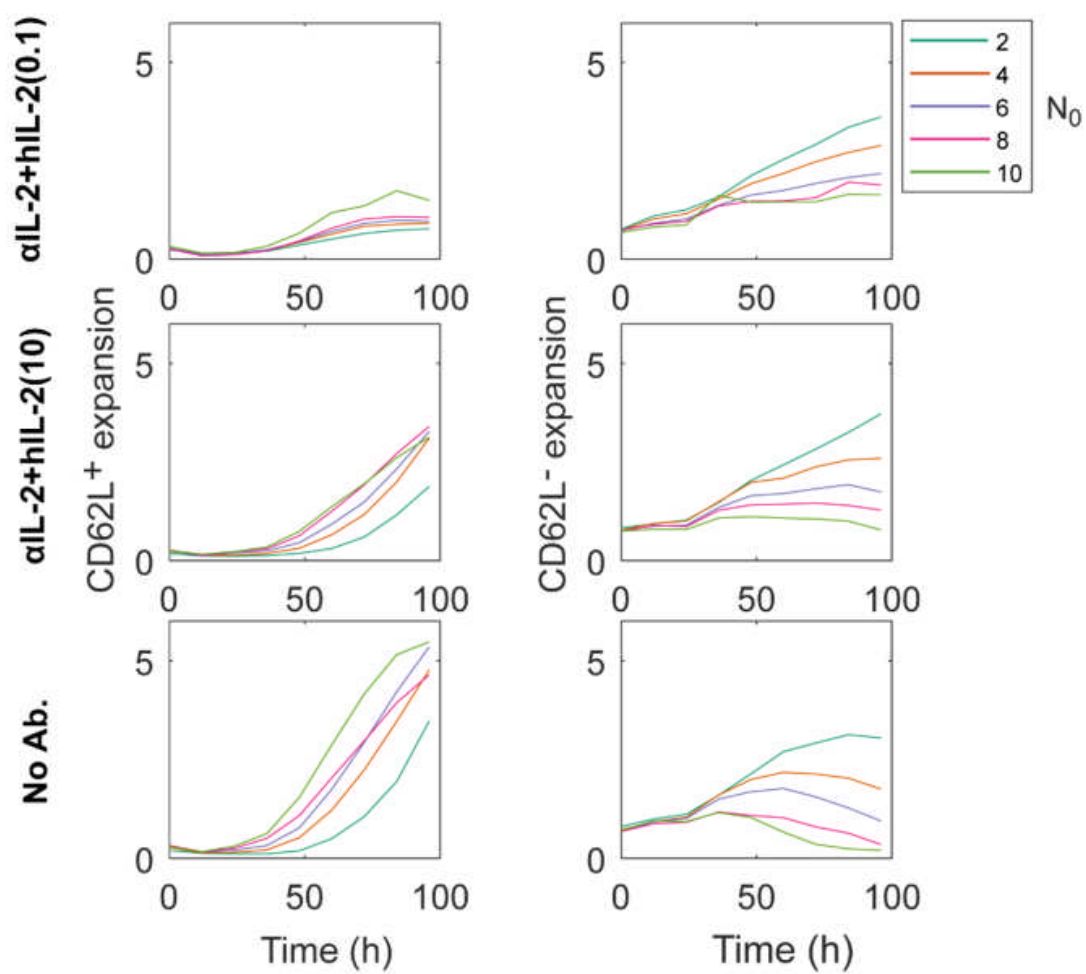

Figure S14. Cell proliferation is reduced when IL-2 is blocked, as well as the expansion of CD62L $\mathrm{L}^{+}$cells. A) Average area traces of all microwells cultured with antiIL-2 (10 ng/ml) and external addition of either IL-6 (20 ng/ml) or human IL-2 at high and low concentrations $(0.1$ and $10 \mathrm{ng} / \mathrm{ml}$, respectively), or cultured without addition of antiIL-2 and cytokines ("No Ab."). 1-way ANOVA test with repeated measures, was used to evaluate differences between samples over time. The area traces of microwells supplemented with IL-6 were not significantly different than those supplemented with 10 
$\mathrm{ng} / \mathrm{ml}$ of IL-2. All area traces of samples in which anti-IL-2 was added were significantly different from the traces of the "No Ab" sample (P-value $\left.<10^{-10}\right)$. B) Relative expansion of $\mathrm{CD}^{2} \mathrm{~L}^{+}$(left) and CD62L- (right) cells with addition of anti-IL-2 and external human IL-2 as in A. Traces were averaged for each $N_{0}$ and normalized by the initial area of each trace. Data is of one representative experiment for each condition, out of the total number of experiment listed in Fig S13.

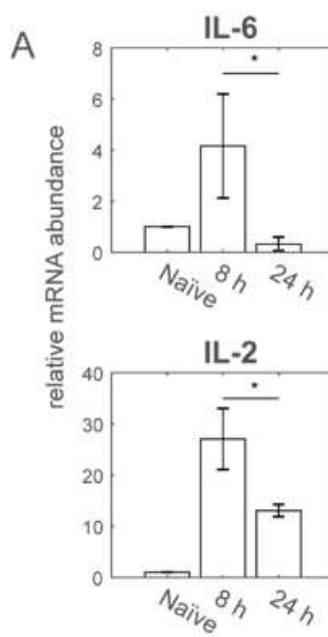

B
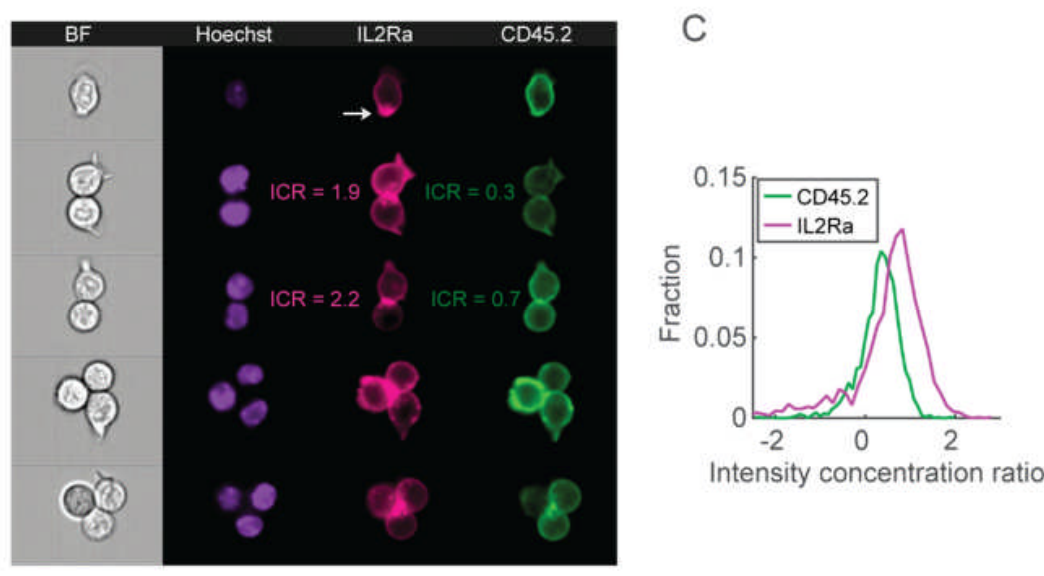

Figure S15. IL-6 and IL-2 are expressed early after activation and IL-2Ra is localized to the cell-cell contact area. A) Relative $I l 6$ and $I l 2 \mathrm{mRNA}$ abundance from naïve and activated $\mathrm{CD}^{+} \mathrm{T}$ cells. Cells were cultured at a concentration of $10^{6}$ cells $/ \mathrm{ml}$ and activated using microbeads. At the indicated time, total RNA was isolated. Il6 and Il2 mRNA was evaluated using qPCR, using the $\Delta \Delta \mathrm{Ct}$ method with Hprt as a reference gene and the "Naïve" as the reference sample. Data are from $n=3$ mice, and the error-bars represent SD. Reported P-values were obtained using a two-sided Student's $t$-test. P $<0.05$. B-C) Imaging flow cytometry analysis of naïve CD4 T cells activated in bulk for $24 \mathrm{~h}$, and stained for IL-2Ra and CD45.2. B) Representative images of single cells, cell doublets, and cell triplets. The intensity concentration ratio (ICR) values for cell doublets are indicated. The ICR is calculated as the labeling intensity at the cell-cell junction divided by the total labeling intensity on the doublet mask. Higher values indicate localization of the labeled 
molecule at the cell-cell contact area. C) Distribution of ICR values for all cell pairs from one representative experiment, comparing IL-2Ra and CD45.2.

A
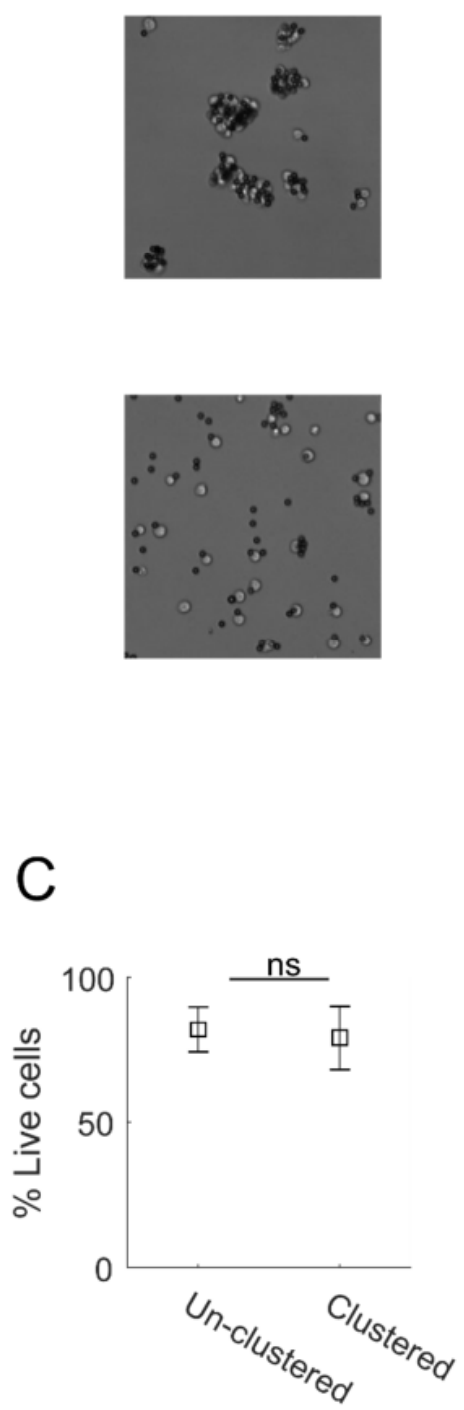

B
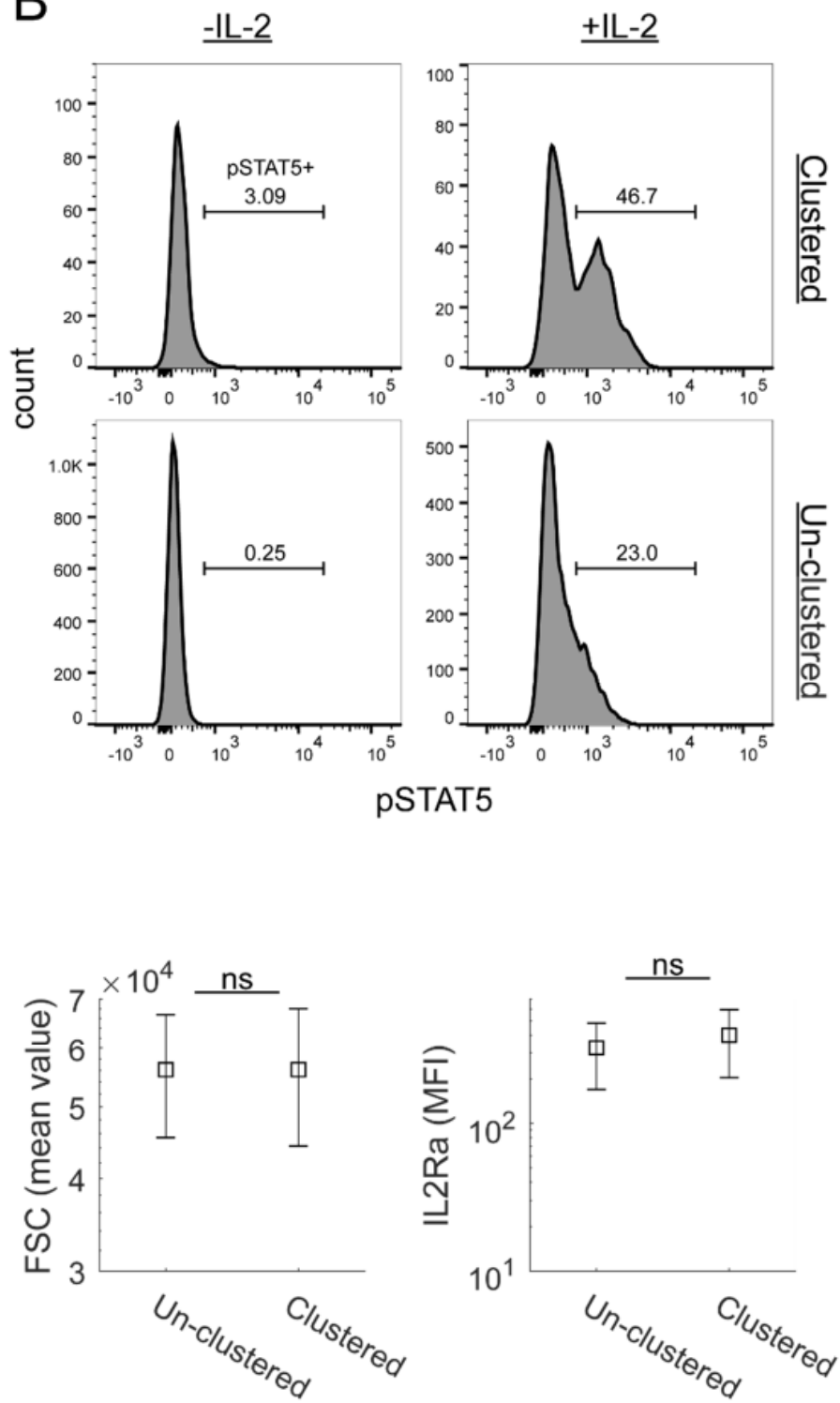

Figure S16. STAT5 phosphorylation in clustered and detached cells. Naïve CD4 T cells were cultured in 24-well plates at a concentration of $10^{6}$ cells $/ \mathrm{ml}$ and activated using activation micro-beads. Culture medium was supplemented with anti-IL-2 (10 $\mu \mathrm{g} / \mathrm{ml})$ to prevent endogenous IL-2 binding. After $24 \mathrm{~h}$, clustered and un-clustered cells were 
separated using a $10 \mu \mathrm{m}$ mesh. Cells were then fixed and labeled for pSTAT5 and IL2Ra (see methods for experimental protocol). A) Representative images of clustered (top) and un-clustered (bottom) fractions directly after separation by the mesh. B) pSTAT5 expression in a representative sample of clustered cells (top), with or without $5 \mathrm{~min}$ pulse of $10 \mathrm{ng} / \mathrm{ml}$ IL-2 ("+IL-2", "-IL-2" respectively) and of un-clustered cells (bottom, with or without IL-2). The percentage of $\mathrm{pSTST}^{+}$cells is indicated in each plot. C) Comparing clustered and un-clustered cells. Left: fraction of live cells; middle: mean FSC (as an indicator of cell size); right: IL2Ra MFI.

Table S1. 1-way ANOVA comparing over initial cell numbers

\begin{tabular}{lll}
\hline Data presented in & Response variable & P-value \\
\hline Fig. 1C top & \% pTCM - OVA activation & 0.002193 \\
\hline Fig. 1C bottom & $\%$ pTCM - beads activation & 0.001669 \\
\hline Fig. S1D & \% pTCM - PMA+ionomycin activation & 0.000118 \\
\hline Fig. S1C & CD62L MFI & $1.60 \mathrm{E}-05$ \\
\hline Fig. S1C & CD44 MFI & $1.41 \mathrm{E}-06$ \\
\hline Fig. S1C & CD25 MFI & 0.818961 \\
\hline Fig. S1C & CD69 MFI & 0.77833 \\
\hline Fig. 2C & Fraction CD62L ${ }^{+}$ & $1.15 \mathrm{E}-56$ \\
\hline Fig. 2C & Fraction CD44 ${ }^{+}$ & 0.271784 \\
\hline Fig. 2F & Ac & 0.322181 \\
\hline Fig. 2G & Tc & $2.28 \mathrm{E}-23$ \\
\hline Fig. S5D & Fraction CD62L ${ }^{+}$over initial bead number & 0.1838 \\
\hline
\end{tabular}


Table S2. 2-way ANOVA for CDC data presented in Fig. 5A and in Fig. S13B.

\begin{tabular}{lll}
\hline Description & Comparison & \multicolumn{1}{l}{ P-value } \\
\hline Cytokine & “+anti-IL-6” Vs. “No Ab.” & 0.001055 \\
\hline Cytokine & “+IL-6(20)” Vs. “No Ab.” & 0.357448799 \\
\hline Cytokine & “+anti-IL-2+IL-6(20)” Vs. “No Ab.” & $1.11 \mathrm{E}-05$ \\
\hline Cytokine & “+anti-IL-2+IL-2(0.1)” Vs. “No Ab.” & $3.99 \mathrm{E}-05$ \\
\hline Cytokine & “+anti-IL-2+IL-2(10)” Vs. “No Ab.” & 0.800144274 \\
\hline Surface molecule & “+Slamf6--6، Vs. “No Ab.” & $4.54 \mathrm{E}-05$ \\
\hline Surface molecule & “+anti-LFA-1” Vs. “No Ab.” & 0.436013245 \\
\hline Surface molecule & “+ICAM-1” Vs. “No Ab.” & 0.051919157 \\
\hline
\end{tabular}

Table S3. Repeated measures analysis of variance, comparing between initial cell numbers over time.

\begin{tabular}{llll}
\hline Data presented in & Response variable & Type & P-value \\
\hline Fig. 2E & Total area expansion & Data & 0.124601 \\
\hline Fig. 3D - left & CD62 $\mathrm{L}^{+}$area expansion & Data & $3.29 \mathrm{E}-23$ \\
\hline Fig. 3E - left & CD62 $\mathrm{L}^{-}$area expansion & Data & $1.38 \mathrm{E}-18$ \\
\hline Not presented & Total cell number expansion & Sim. & 0.533759 \\
\hline Fig. 3D - right & CD62 $\mathrm{L}^{+}$cell number expansion & Sim. & $1.21 \mathrm{E}-12$ \\
\hline Fig. 3E - right & CD62 $\mathrm{L}^{-}$cell number expansion & Sim. & $3.79 \mathrm{E}-41$ \\
\hline
\end{tabular}


Table S4. Antibody specifications

\begin{tabular}{|c|c|c|c|c|}
\hline Antibody & Format & Clone & $\begin{array}{l}\text { Purchased } \\
\text { from }\end{array}$ & Usage \\
\hline anti-IL-2 & Purified & JRS6-1A12 & Biolegend & Cell culture \\
\hline anti-IL-6 & Purified & MP5-20F3 & Biolegend & Cell culture \\
\hline anti-IL-6Ra & Purified & D7715A7 & Biolegend & Cell culture \\
\hline $\begin{array}{l}\text { anti-IL-15/IL- } \\
15 R\end{array}$ & Purified & GRW15PLZ & eBioscience & Cell culture \\
\hline anti-LFA-1 & Purified & M17/4 & Biolegend & Cell culture \\
\hline \multirow[t]{3}{*}{ anti-CD62L } & $\mathrm{PE}$ & MEL-14 & Biolegend & Live stain \\
\hline & PE-Cye 7 & MEL-14 & Biolegend & Flow Cytometry \\
\hline & APC & MEL-14 & Biolegend & Flow Cytometry \\
\hline \multirow[t]{4}{*}{ anti-CD44 } & FITC & IM7 & Biolegend & Live Stain \\
\hline & APC & IM7 & Biolegend & Live Stain \\
\hline & APC-Cye7 & IM7 & Biolegend & Flow Cytometry \\
\hline & PE-Cy7 & IM7 & Biolegend & FlowCytometry \\
\hline \multirow[t]{3}{*}{ anti-CD4 } & FITC & RM4-5 & Biolegend & Flow Cytometry \\
\hline & $\mathrm{PE}$ & RM4-5 & Biolegend & Flow Cytometry \\
\hline & Pacific-Blue & RM4-5 & Biolegend & Flow Cytometry \\
\hline \multirow[t]{3}{*}{ anti-IL-2Ra } & APC & PC61 & Biolegend & $\begin{array}{l}\text { ImageStrem and } \\
\text { Flow Cytometry }\end{array}$ \\
\hline & $\begin{array}{l}\text { PerCp- } \\
\text { Cy5.5 }\end{array}$ & PC61 & Biolegend & Flow Cytometry \\
\hline & APC-Cy7 & PC61.5 & ebioscience & ImageStrem \\
\hline
\end{tabular}




\begin{tabular}{|l|l|l|l|l|}
\hline & $\begin{array}{l}\text { AlexaFluor- } \\
488\end{array}$ & PC61 & Biolegend & Confocal microscopy \\
\hline anti-CD69 & PE & H1.2F3 & Biolegend & Flow Cytometry \\
\hline anti-pSTAT5 & FITC & SRBCZX & ebioscience & Flow Cytometry \\
\hline anti-CD45.2 & APC & 104 & Biolegend & Live Stain \\
\cline { 2 - 6 } & $\begin{array}{l}\text { Alexa } \\
\text { Flour488 }\end{array}$ & 104 & Biolegend & ImageStrem and \\
\hline anti-CD45.1 & APC-Cy7 & A20 & Biolegend & Flow Cytometry \\
\hline anti-KLRG1 & $\begin{array}{l}\text { PerCp- } \\
\text { Cy5.5 }\end{array}$ & 2F1/KLRG1 & Biolegend & Flow Cytometry \\
\hline anti-CD27 & $\begin{array}{l}\text { Brilliant } \\
\text { violet 510 }\end{array}$ & LG.3A10 & Biolegend & Flow Cytometry \\
\hline anti-IL-6st & PE & 4H1B35 & Biolegend & Confocal microscopy \\
\hline
\end{tabular}

Table S5. qPCR primers

\begin{tabular}{|l|l|l|}
\hline Hprt & 5'- AGCCTAAGATGAGCGCAAGT -3' & 5'- TTACTAGGCAGATGGCCACA -3' \\
\hline Il6 & 5'- CTCTGGGAAATCGTGGAAAT -3' & 5'- CCAGTTTGGTAGCATCCATC -3' \\
\hline Il2 & 5'-TCAGCAACTGTGGTGGACTT-3' & 5'- AGGGCTTGTTGAGATGATGCT -3' \\
\hline
\end{tabular}

\section{Movie S1}

Cells proliferating and differentiating in a microwell over $96 \mathrm{~h}$.

\section{References}

30. I. Zaretsky et al., Monitoring the dynamics of primary T cell activation and differentiation using long term live cell imaging in microwell arrays. Lab Chip. 12, 5007-15 (2012). 
48. C. Trapnell, L. Pachter, S. L. Salzberg, TopHat: Discovering splice junctions with RNA-Seq. Bioinformatics. 25, 1105-1111 (2009).

49. S. Heinz et al., Simple Combinations of Lineage-Determining Transcription Factors Prime cis-Regulatory Elements Required for Macrophage and B Cell Identities. Mol. Cell. 38, 576-589 (2010).

50. M. I. Love, W. Huber, S. Anders, Moderated estimation of fold change and dispersion for RNA-seq data with DESeq2. Genome Biol. 15, 550 (2014). 